\title{
A gastroenterologist's perspective of the medical management of patients with Crohn's disease and ulcerative colitis
}

\author{
ABR THOMSON MD PhD FRCPC FACP FRS FACC
}

\begin{abstract}
ABR THOMSON. A gastroenterologist's perspective of the medical management of patients with Crohn's disease and ulcerative colitis. Can J Gastroenterol 1996;10(1): 49-62. Medical therapy in patients with inflammatory bowel disease (IBD) has specific objectives that need to be remembered when considering any form of intervention. These objectives include to improve the quality of life, to improve symptoms, to improve nutrition and reduce the risk of nutritional deficiencies, to reduce the frequency and severity of recurrences, to reduce complications, including the need for surgery, and to cure the disease. Medical therapy potentially helps to achieve all of these objectives for sufferers of IBD, except the last one - until the pathogenesis of the recurrent or continuous episodes of bowel inflammation is better understood, this last objective will remain "a riddle, wrapped in a mystery, inside an enigma".
\end{abstract}

Key Words: 5-aminosalicylic acid (5-ASA), Immunosuppressants, Steroids, Therapy
Point de vue d'un gastro-entérologue sur le traitement médical des patients atteints de maladie de Crohn et de colite ulcéreuse

RÉSUMÉ : Le traitement médical chez les patients atteints de maladie inflammatoire de l'intestin répond à des objectifs spécifiques qui doivent être tenus en ligne de compte lorsque l'on intervient. Ces objectifs sont notamment : améliorer la qualité de vie, atténuer les symptômes, améliorer la nutrition et réduire les risques de déficit nutritionnel, réduire la fréquence et la gravité des récurrences, réduire les complications, y compris le recours à la chirurgie et guérir la maladie. Le traitement médical peut contribuer à l'atteinte de tous ces objectifs pour les personnes qui souffrent de MII, à l'exception du dernier; tant que la pathogenèse de la récurrence ou de la persistance des symptômes de la maladie inflammatoire ne sera pas mieux comprise, ce dernier objectif sera hors de notre portée.

$\mathrm{R}$ easons for the chronic relapsing nature of Crohn's disease (CD) and chronic idiopathic ulcerative colitis (UC) are unknown. Certain factors have been described in association with symptomatic recurrences, such as use of nonsteroidal anti-inflammatory drugs (NSAIDs), intercurrent viral illness, emotional stress, pregnancy, development of diarrhea masquerading as active disease in a patient on antibiotics, the rare worsening of symptoms with sulfasalazine, discontinuation of maintenance therapy and change in

smoking habits. It is important to establish the cause of recurrences. It is, however, recognized that many more persons will have endoscopically active $\mathrm{CD}$ after a previous surgical resection than will have symptoms (1). It is unclear whether the objective of therapy should be to control symptoms or to control disease activity (as measured endoscopically, microscopically or biochemically). Knowing the pathophysiological factors responsible for causing the inflammation or

An abbreviated list of references appears at the end of this paper. A full list is available from the corresponding author

Division of Gastroenterology, and Nutrition and Metabolism Research Group, University of Alberta, Edmonton, Alberta

Correspondence: Dr ABR Thomson, 519 Newton Research Building, University of Alberta, Edmonton, Alberta T6G 2C2. Telephone 403-492-6490, fax 403-492-7964, e-mail alan.thomson@ualberta.ca

This paper was presented at the Trends in Inflammatory Bowel Disease Therapy meeting, April 6 to 9, 1994, held in Victoria, British Columbia. This paper has also been published in Sutherland LR, et al, eds. Inflammatory Bowel Disease: Basic Research, Clinical Implications and Trends in Therapy. Boston, Dordrecht and London: Kluwer Academic Publishers, 1994 
causing the inflammation to become symptomatic would be useful.

Several clinical indexes have been developed to assess the activity of CD, such as the widely used Crohn's disease activity index (CDAI) (2). Uses and limitations of these indexes have been reviewed (3). Clinical indexes have also been developed for patients with UC. Objective markers of continued disease activity need to be developed and used to predict future clinical recurrences. For example, intestinal permeability is abnormal in patients with active $\mathrm{CD}$, and may return towards normal when the disease becomes clinically inactive. Should medical treatment be continued until this altered permeability is normalized? What does the increased permeability indicate about underlying immunological or vascular abnormalities? Furthermore, it is difficult to know how best to define relapse: symptoms, laboratory values or endoscopic appearances (3)? Consider, for example, that it is unknown whether abnormal laboratory measures of disease activity should signal treatment in asymptomatic individuals, or should be used as an end-point for therapy rather than attempting to achieve the rather arbitrary reduction in the CDAI to less than 150 units.

It is important to consider several concepts. First, treating symptoms does not necessarily alter disease activity, prevent complications or change the natural history of inflammatory bowel disease (IBD). Second, it is important to distinguish between the treatment of active disease and continuous disease activity suppression, and true maintenance of remission. Next, predictors of recurrence versus predictors of continued disease activity need to be developed. Fourth, improved quality of life (QOL) is likely to be achieved with treatments that reduce the frequency and severity of symptoms, so changes in disease activity indexes should be correlated with changes in QOL indexes. Finally, the costeffectiveness of all medical and surgical treatments for IBD need to be assessed against the background of improving QOL. Each of the major therapeutic options available for the medical management of patients with $\mathrm{UC}$ or $\mathrm{CD}$ will be considered. These include the anti-inflammatories (sulfasalazine, mesalamines, $5^{\prime}$-lipoxygenase inhibiters and $\omega-3$ fatty acids), antibiotics, glucocorticosteroids (GS), immunomodulators (azathioprine [AZA], 6-mercaptopurine [6-MP], cyclosporine, methotroxate, immunoglobulin and $\mathrm{K}-76$ ), nutritional therapy, lifestyle modification and numerous as yet unproven experimental agents.

\section{ANTI-INFLAMMATORIES}

Sulfasalazine: Sulfasalazine, composed of a sulfa moiety (a sulfonamide, sulfapyridine), is covalently bonded through an azo-bond to an acetylsalicylic acid analogue, mesalamine (5-aminosalicylic acid [5-ASA]). Sulfasalazine is cleaved by the enzyme azo-reductase, found in enteric bacteria, to yield its constituent moieties, sulfapyridine and 5-ASA. While the sulfapyridine is often viewed as an inactive 'carrier', it may, in fact, partially contribute to the clinical effectiveness of sulfasalazine.

Mesalamine confers its anti-inflammatory activity largely as the result of local action on the bowel. Mesalamine inhibits interleukin production, platelet activating factor, and chemotaxis of neutrophils and monocytes. Also, it is a potent scavenger of oxygen free radicals and affects the inflammatory process through leukotrienes and prostaglandins (4). Although there are many actions of 5-ASA, the ones that are important for the therapeutic response in IBD patients are unknown.

A major advance in the management of patients with UC was the introduction of sulfasalazine for maintenance therapy. The efficacy of sulfasalazine in the management of patients with a mild to moderate attack of UC and in the maintenance of clinical remission has been reviewed in a detailed meta-analysis (5). For example, a relapse rate of $14 \%$ over three years was observed with sulfasalazine $2 \mathrm{~g} /$ day, much lower than with placebo (56\%) (6). Adverse effects of sulfasalazine occur in at least $15 \%$ of patients using sulfasalazine and may vary from minor inconvenience to major allergic reaction.

The use of sulfasalazine in $\mathrm{CD}$ is limited to the relatively modest effect in patients with colonic or ileocolonic disease, as seen in the National Cooperative Crohn's Disease Study (NCCDS) (7) or to colonic and ileal disease (8). In the NCCDS, sulfasalazine was not found to be effective in CD relapse prevention (9). On the other hand, sulfasalazine $3 \mathrm{~g} /$ day for two years appears to be beneficial to prevent postoperative recurrences of CD (10).

Mesalamine by mouth: Use of the new 5-ASA preparations in patients with $C D$ and $U C$ has been reviewed (11-13). It is generally accepted that mesalamine is therapeutically equivalent to sulfasalazine for treatment of active UC and for maintaining remission in this disease (14-20). Importantly, mesalamine products have different delivery properties and they are not necessarily equivalent in beneficial action. Thus, efficacy proven from a clinical trial of one mesalamine compound cannot necessarily be compared directly with that of another 5-ASA compound with a different coating. Both sulfasalazine and mesalamine may be useful to treat active $C D$, and mesalamine, but not sulfasalazine, is effective maintenance therapy in $\mathrm{CD}(21,22)$.

Asacol $4.8 \mathrm{~g} /$ day (enteric-coated 5-ASA; Procter \& Gamble Pharmaceuticals) yielded a clear benefit in patients with mild attacks of UC (23). Miglioli and colleagues (24) compared the efficacies of Asacol 1.2, 2.4 and $3.6 \mathrm{~g} /$ day in a multicentre trial including $73 \mathrm{UC}$ patients with mild attacks. After one month of treatment, $46 \%$ of patients who used $3.6 \mathrm{~g} /$ day were in remission compared with $12 \%$ of those receiving $1.2 \mathrm{~g} /$ day. Although the $3.6 \mathrm{~g} /$ day dose yielded better results, the response rate was still only modest. Sninsky et al (25) obtained approximately comparable results.

Asacol $3.2 \mathrm{~g} /$ day by mouth yields results equivalent to those of low dose topical steroid enemas (prednisolone $20 \mathrm{mg} /$ day) over a four-week interval for the treatment of patients with distal colitis (26); this finding apparently allows patients to choose an oral or a topical approach for treatment of mild disease.

Olsalazine (Dipentum; Pharmacia Upjohn) 3 g/day is su- 
perior to placebo for the treatment of mild attacks of active UC (27). Olsalazine $1 \mathrm{~g} /$ day in $114 \mathrm{UC}$ patients was compared with sulfasalazine $2 \mathrm{~g}$ /day in 112 patients for maintenance therapy (28). Patients were admitted to the study within one month of remission after an attack, and rates were similar in both groups: about $45 \%$ in a year. On the other hand, it has been suggested that relapse rates are lower in UC patients treated with olsalazine than with sulfasalazine or other mesalamines (15-17). The issues are whether sulfasalazine is more effective than an equivalent amount of 5-ASA; whether higher doses of 5-ASA may be used to achieve even lower relapse rates; and whether one 5-ASA preparation is superior to another in the equivalent clinical setting.

Bioavailability, plasma level and excretion of the slow-release 5-ASA preparations have been reviewed $(13,29)$. Absorption of delayed-release oral mesalamine is not modified by dietary fibre intake (30). Asacol, Salofalk (enteric-coated 5-ASA; Axcan Pharma), Pentasa (entericcoated 5-ASA; Hoechst-Marion-Roussel) and Dipentum, each given as $2 \mathrm{~g}$ /day for five days in 14 patients with $\mathrm{UC}$ in remission, were compared (31). The mesalamine concentration in the colonic lumen (estimated with the rectal dialysis technique) was doubled after olsalazine use compared with Pentasa or Salofalk, but was not greatly different after using Asacol. Conversely, systemic concentrations of mesalamine were lower in patients who took olsalazine than in those who took Salofalk or Pentasa, results similar to those of another comparative study (32). De Vos et al (33) evaluated intramucosal (versus intraluminal) mesalamine and acetylated mesalamine concentrations in ileocolonic biopsy specimens of 61 patients with IBD who took different preparations of mesalamine for one week. The highest concentrations of native and acetylated mesalamine were seen after administration of Asacol, with lower concentrations noted after use of sulfasalazine or Dipentum. This information is useful to help select a new 5-ASA for colonic delivery for patients in remission, but mesalamine release may not be as favourable with azo derivatives as it is in patients in remission (34).

Oral mesalamines have shown favourable results in patients with active $\mathrm{CD}$ in an American multicentre study of 310 patients who received placebo or Pentasa 1,2 or $4 \mathrm{~g} /$ day for 16 weeks (35); 64\% of CD patients went into remission while on Pentasa $4 \mathrm{~g} /$ day. It was surprising that there was no clear-cut dose-dependent response in this study (Figure 1). Pentasa $1.5 \mathrm{~g} /$ day may (29) or may not (36) be useful to treat patients with active CD. Salofalk $3 \mathrm{~g} /$ day over 12 weeks is comparable with prednisone $40 \mathrm{mg} /$ day for two weeks, with subsequent dose reduction, in the treatment of active CD, although the initial clinical response was faster with prednisone (37) (Figure 2).

CD patients given Mesasal (enteric-coated 5-ASA; SmithKline Beecham) (also known as Claversal in Europe) $1.5 \mathrm{~g} /$ day versus placebo in a one-year study showed lower relapse rates, especially those with ileal disease, males or patients following ileal resection (22). A large multicentre study with Claversal $3 \mathrm{~g} /$ day versus placebo has been com-

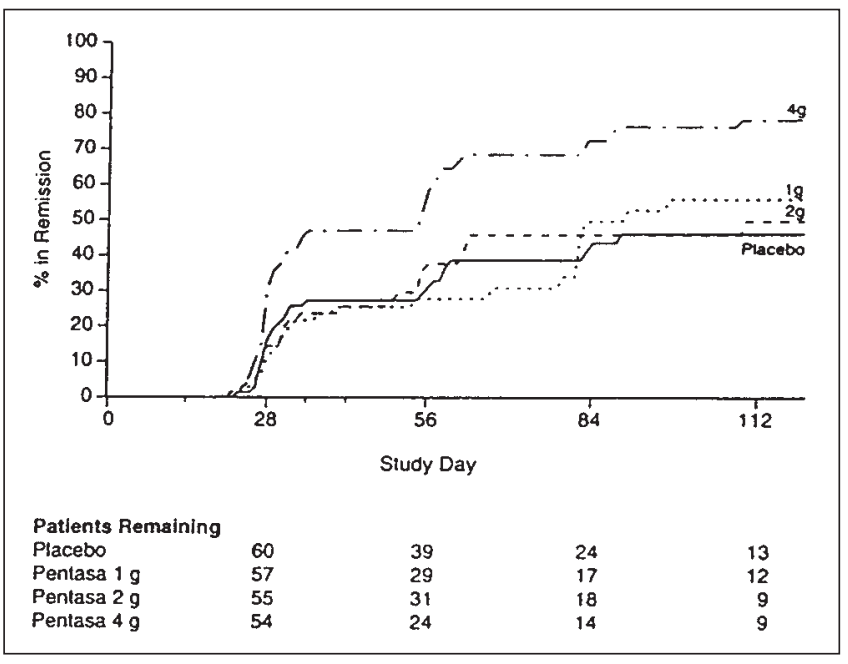

Figure 1) Mesalamine lifetable plot: percentage of patients achieving remission in each treatment group at each study visit (Kaplan-Meier method). Reproduced with permission from reference 35

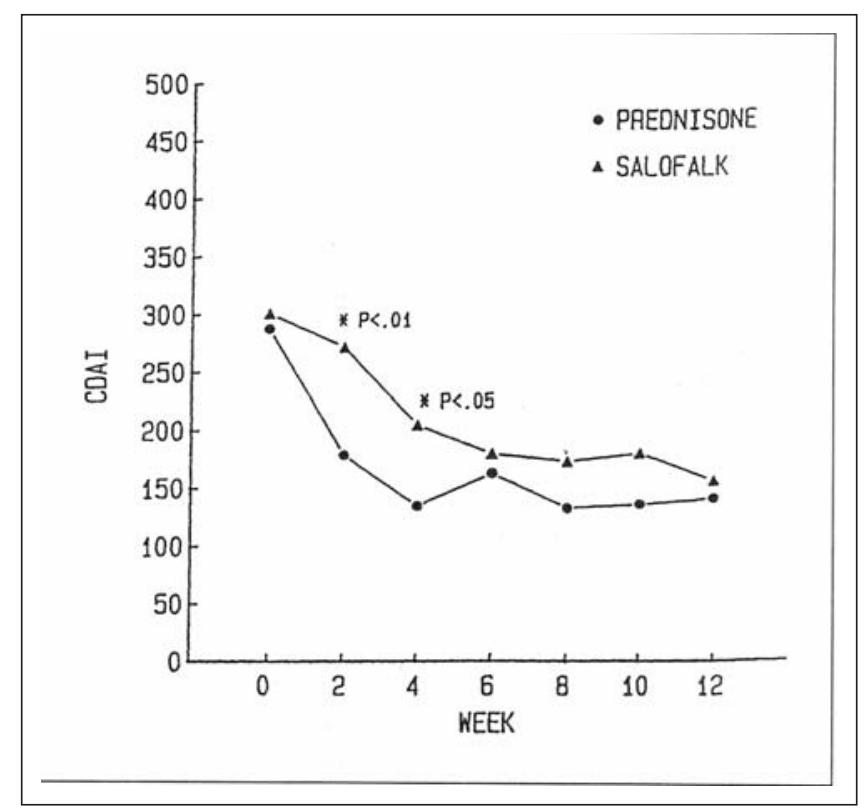

Figure 2) Mean Crohn's disease activity index (CDAI) score changes obtained at each two-week visit in all studied patients in a multicentre controlled trial of 5-aminosalicylic acid versus prednisone. Reproduced with permission from reference 37

pleted but the results are not yet available (unpublished data). A French multicentre study with Pentasa 2 g/day showed benefit only in CD patients admitted with a flare-up of disease within three months of the study (38) (Figure 3). In contrast, a one-year Danish multicentre study using Pentasa $1.5 \mathrm{~g}$ bid or placebo in 202 patients with inactive CD showed no benefit using the 5-ASA treatment (39). A recently completed Canadian maintenance study with Pentasa $3 \mathrm{~g} /$ day showed superiority over placebo (personal communication). An open study has suggested that Pentasa may be useful to treat $C D$ patients whose disease is active or in re- 


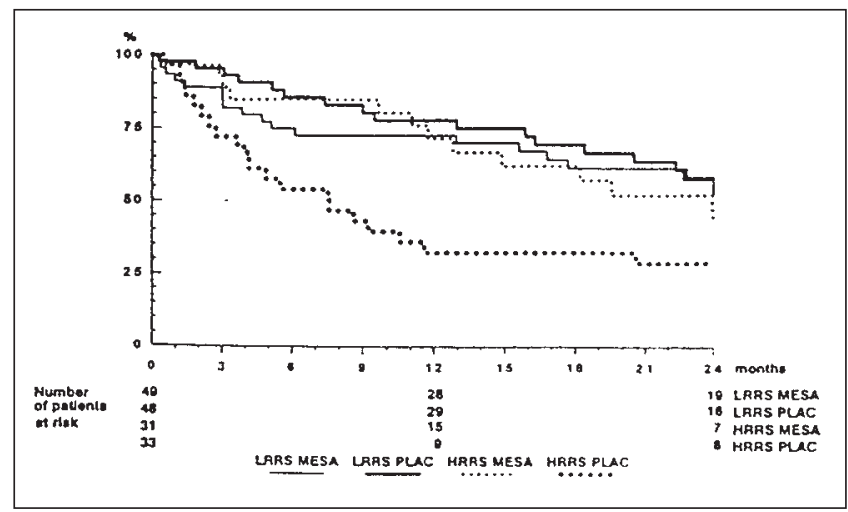

Figure 3) Kaplan-Meier lifetable curves of maintaining remission in the four treatment groups. HRRS High risk of recurrence; LRRS Low risk of recurrence; MESA Mesalamine; PLAC Placebo. Reproduced with permission from reference 38

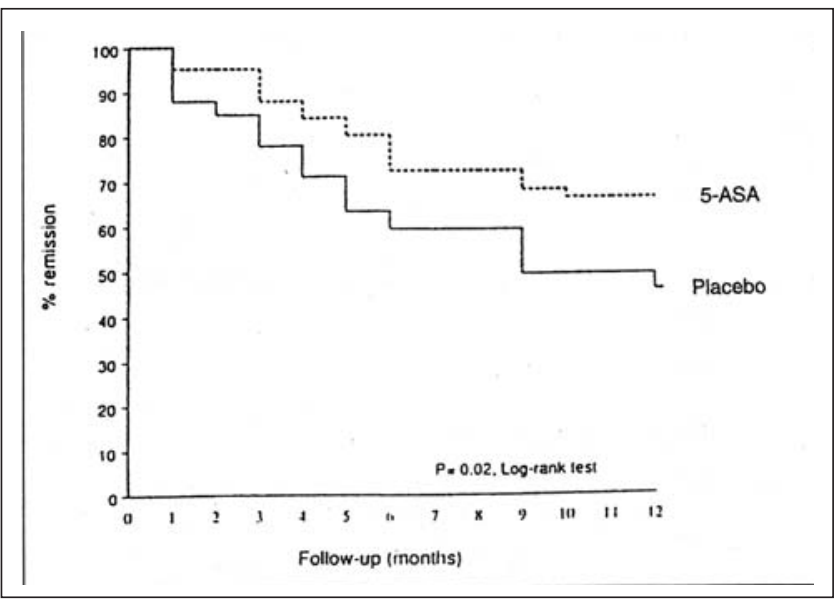

Figure 4) Lifetable estimate of maintaining remission during treatment with 5-aminosalicylic acid (5-ASA) or placebo. Reproduced with permission from reference 41

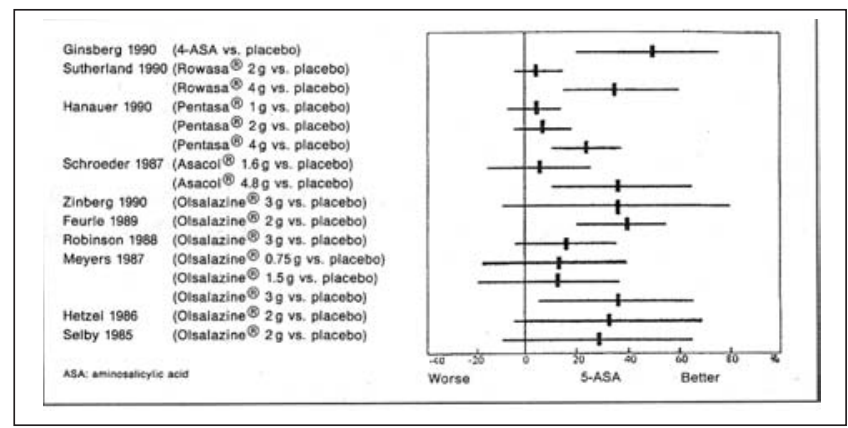

Figure 5) 5-ASA in ulcerative colitis acute treatment. Reproduced with permission from $\operatorname{Dr} L$ Sutherland. A full list of references is available from the author

mission (40). In an Italian multicentre placebo controlled study of $125 \mathrm{CD}$ patients with a CDAI lower than 150, patients on Asacol $800 \mathrm{mg}$ tid had a yearly relapse rate of $34 \%$ versus the $55 \%$ one-year relapse rate observed in patients on placebo (41) (Figure 4). The efficacy of long term use of oral mesalamine has also been demonstrated in asymptomatic
CD patients who had laboratory signs suggestive of disease activity (42), with fewer subsequent symptomatic relapses in patients on mesalamine. Caprilli and colleagues (43) reported that Asacol $2.4 \mathrm{~g} /$ day helped to reduce recurrences postoperatively in CD patients, and McLeod et al (44) recently reported that Salofalk $3 \mathrm{~g} /$ day reduced clinical and endoscopic signs of recurrent postoperative $\mathrm{CD}$, as well as complications and the need for reoperation. Using 5-ASA preparations for maintenance therapy in $\mathrm{CD}$ has been thoughtfully questioned (45). However, two meta-analyses performed on published data confirmed clinical efficacy of mesalamine but not sulfasalazine in the maintenance of remission in CD patients $(21,46)$. Because of a therapeutic gain of approximately 30\% (ie, about 30\% fewer patients with $\mathrm{CD}$ will have a symptomatic recurrence when treated with mesalamine for 12 months) and because the clinical remissions are often milder, the use of mesalamine remains open for discussion and review. Maintenance therapy with 5-ASAs in CD certainly looks favourable, and cost-efficacy should be evaluated. Attempts should also be made to determine what characteristics of the CD patient and the disease best predict response to maintenance therapy.

The only obvious clinical benefits of mesalamine versus sulfasalazine in the treatment of active $\mathrm{UC}$ or $\mathrm{CD}$ are lower prevalence of adverse effects (3\% versus 30\%, approximately), including fewer serious side effects, and equivalent cost for some but not all mesalamine preparations (13). Thus, favourable safety profile is the primary advantageous characteristic of the mesalamines; their use has almost completely eradicated dose-dependent side effects including male infertility. Allergic reactions have also been greatly reduced, but other side effects such as pancreatitis (47) and interstitial nephritis (48) are still described, but are very uncommon. Thus, the mesalamine compounds have clinical efficacy approximately comparable with sulfasalazine, with generally fewer adverse effects (49-51). This was not observed in one study with olsalazine (52), whereas in another study olsalazine was beneficial and free from side effects in nearly $87 \%$ of patients intolerant of sulfasalazine (53). Both sulfasalazine and mesalamine appear to be safe to use in pregnancy (54).

The new 5-ASA compounds are clearly superior to placebo in the treatment of patients with active UC (Figure 5), whereas only the higher dose of Pentasa is superior to placebo in the treatment of patients with active CD (Figure 6). As shown in Figure 7, 5-ASAs are comparable with equivalent doses of sulfasalazine to maintain remission in UC, whereas three of six trials demonstrate superiority of 5-ASA versus placebo to maintain remission in $\mathrm{CD}$ patients (Figure 8).

Is there a role for combination therapy of sulfasalazine/ 5 ASA with another class of drug? A Dutch trial compared the value of sulfasalazine alone ( 4 to $6 \mathrm{~g} /$ day) versus a combination of the same does of sulfasalazine plus prednisolone ( 30 $\mathrm{mg} /$ day for two weeks, then reduced) for a 16-week, doubleblind study using the Dutch or the Van Hees Activity Index (VHAI) and the CDAI (55) as the primary outcome vari- 
ables (Figure 9). Sixty patients completed the study; those who received the combined treatment manifested a significantly faster initial six-week clinical improvement (according to the VHAI only), but at the end of the study shared results similar to those receiving sulfasalazine alone (using both the CDAI and the VHAI). Some critical questions have been asked regarding the use of combination therapy, such as differences in baseline conditions, the relatively small number of patients and the lack of a placebo controlled group (56). Nonetheless, once a decision has been made to use GS, the addition of sulfasalazine to GS appears to offer the patient some potential therapeutic advantage. Although not specifically studied, it is likely that the combination of GS plus 5-ASA will be as useful as GS plus sulfasalazine.

Mesalamine by enemas or suppositories: Topical mesalamine is established therapy for the treatment of active disease as well as maintenance of remission in left-sided UC or proctitis (57-61). Mesalamine enemas are efficacious in the treatment of disease extending to the level of the splenic flexure. The response to mesalamine enemas is typically about $80 \%$, with onset of clinical improvement observed in three to 21 days (62). A recent meta-analysis of 17 randomized, doubleblind controlled trials of UC distal to the splenic flexure demonstrated dramatic improvement with topical 5-ASAs compared with placebo, with odds ratios of 7.36 to 10.59 for active disease and 16.22 for quiescent disease (63).

To determine the optimal dose of topical treatment, a dose-ranging study using enemas containing placebo or 1,2 or $4 \mathrm{~g}$ mesalamine was carried out in 113 patients with mild to moderate attacks of UC (64). After one month all patients treated with mesalamine enemas were significantly clinically better than those on placebo. No difference was found among the three concentrations of mesalamine, so doses as low as $1 \mathrm{~g} /$ day appear to be effective. In 90 patients with left-sided UC unresponsive to conventional medical therapy with corticosteroids and sulfasalazine, $87 \%$ improved by at least one grade of endoscopic inflammation after 12 weeks of mesalamine enemas (65). Mesalamine foams are at least as good as enemas (57).

The role of mesalamine suppositories has been reviewed (66). Campieri et al (57) carried out a multicentre study in which the efficacies of suppositories of mesalamine $500 \mathrm{mg}$ bid and tid were compared; both active treatment arms were comparable (about 70\% improvement at one month) and both were superior to placebo.

Similarly, D'Adenzo et al (67) demonstrated the superiority of mesalamine suppositories $400 \mathrm{mg}$ bid versus placebo. Campieri and co-workers (59) also demonstrated the beneficial role of mesalamine suppositories in patients with proctitis.

The optimal dose of mesalamine to be given by suppositories is unknown, as is the comparative efficacy against oral therapy or enemas.

There is the possible need for long term treatment with mesalamine enemas in patients with distal UC, and with suppositories in ulcerative proctitis (67). Treatment usually needs to be continued for at least one month; longer periods

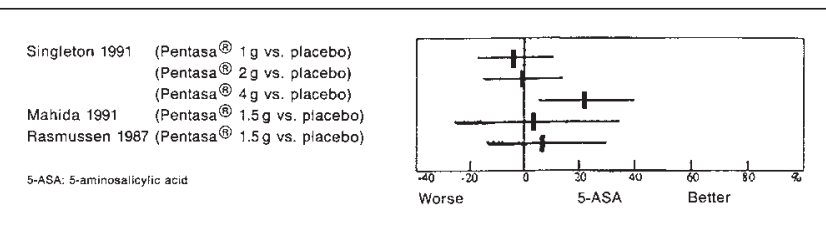

Figure 6) 5-ASA in Crohn's disease active treatment. Reproduced with permission from Dr L Sutherland. A full list of references is available from the author

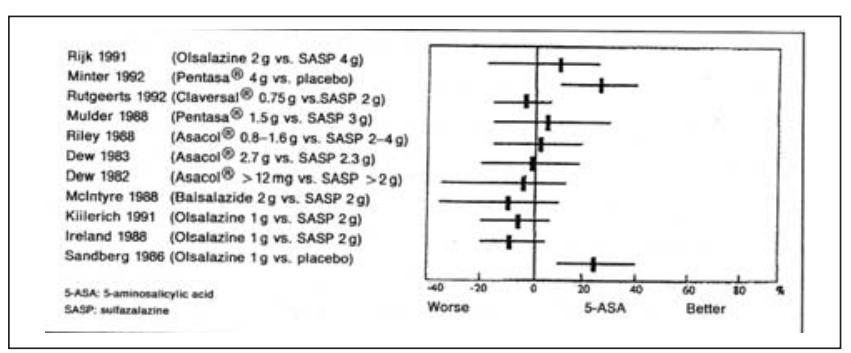

Figure 7) 5-ASA in ulcerative colitis remission maintenance. Reproduced with permission from Dr L Sutherland. A full list of references is available from the author

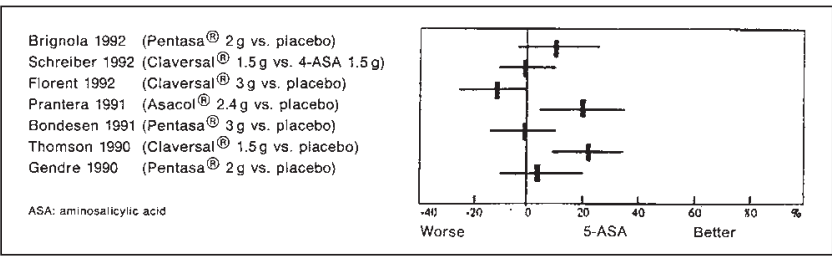

Figure 8) 5-ASA in Crohn's disease remission maintenance. Reproduced with permission from Dr L Sutherland. A full list of references is available from the author

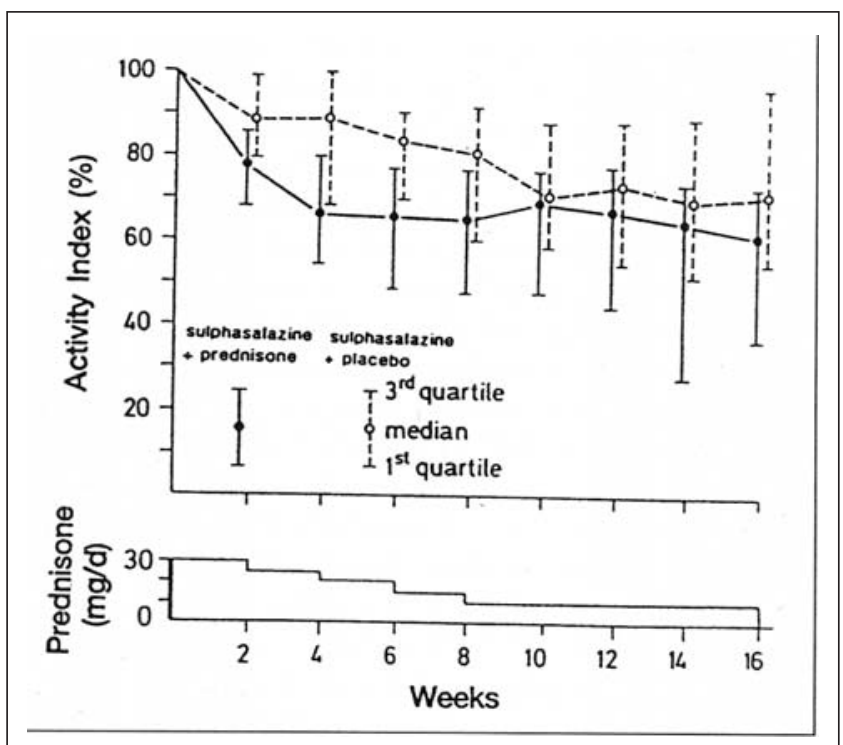

Figure 9) The Van Hees Activity Index as a proportion of the initial value in patients treated with sulfasalazine and prednisone or sulfasalazine and placebo. The daily dose of prednisone in the patients treated with sulfasalazine and prednisone is shown in the bottom panel. Data are presented as medians and quartiles. The median and the first and third quartiles of a sample are the values that include 50\%, 25\% and 75\% of the observations, respectively. Reproduced with permission from reference 55 
may be necessary, and many patients need to continue indefinitely on mesalamine enemas or suppositories taken every one, two or three days.

5'-lipoxygenase inhibitors: Elevated levels of leukotriene B4 $\left(\mathrm{LTB}_{4}\right)$ and prostaglandin $\mathrm{E}_{2}$ have been reported in the rectal dialysates of patients with active UC, which fall or return to normal with clinical disease remission. Selective 5'-lipoxygenase inhibitors and leukotriene receptor antagonists have been developed. A study of Zileutron (a study medication not available commercially) $800 \mathrm{mg} /$ day for 28 days in 11 active UC patients demonstrated improved symptoms, with endoscopic improvement in eight (68). Zileutron $800 \mathrm{mg} /$ day by mouth was tested versus placebo for 28 days in a clinical trial of 71 patients with active UC. Significantly better results were obtained only in Zileutron-treated UC patients not given previous sulfasalazine treatment (69).

In vitro, the 5'-lipoxygenase inhibitor $\mathrm{BW}$ - $\mathrm{A} 4 \mathrm{C}$ reduces $\mathrm{LTB}_{4}$ in rectal biopsies of patients with IBD, without affecting prostaglandin $\mathrm{E}_{2}$ or thromboxane $\mathrm{B}_{2}$ synthesis. The clinical use of $\mathrm{BW}-\mathrm{A} 4 \mathrm{C}$ is unknown.

$\omega-3$ fatty acids: Fish oils are rich in $\omega-3$ fatty acids such as eicosapentaenoic acid (EPA) and docosahexanoic acid. These fatty acids are metabolized by the enzyme $5^{\prime}$-lipoxygenesase to form leukotriene B5 (LTB5) and prostaglandin $\mathrm{E}_{3}$, with subsequent reduction of $\mathrm{LTB}_{4}$ levels. LTB5 does not possess as many of the pro-inflammatory properties as LTB4. Oral supplementation with $\omega-3$ fatty acids or EPA has been examined in patients with active UC. In a multicentre, randomized, double-blind, placebo controlled, crossover trial with four-month treatment periods separated by a one-month washout in 24 patients with UC, Stenson et al (70) gave 18eisapentanoic acid capsules daily $(3.2 \mu \mathrm{g}$ EPA and $2.6 \mu \mathrm{g}$ docosahexanoic acid). Rectal dialysate levels of LTB4 fell, as did histological abnormalities of UC. Aslan and Thadafilopoulos (71) gave 15-eisapentanoic acid tablets or placebo in an eight-month, double-blind, placebo controlled, crossover trial in UC patients; disease activity fell, but there were no changes in histology and LTB4 levels. Solomon et al (72) treated 10 patients with mild to moderate attacks of UC in whom conventional therapy failed. Patients had dietary supplementation with EPA $2.75 \mathrm{~g} /$ day for eight weeks. There was marked improvement in seven, and four of five who continued with GS were able to reduce the dose. The mechanism of action of this steroid-sparing effect is unknown. Thus, fish oil may be useful to manage patients with active UC who do not respond to standard therapy.

EPA is of no benefit in maintenance therapy treatment in UC (73), and the role of EPA in the treatment of patients with active or remitted $\mathrm{CD}$ remains unproven.

\section{ANTIBIOTICS}

In a multicentre American-Canadian study, metronidazole (Flagyl; Rhône-Poulenc Rorer) 10 or $20 \mathrm{mg} / \mathrm{kg} /$ day for 16 weeks was tested against placebo in patients with active CD (74). Both doses of metronidazole were superior to placebo, especially in patients with colonic disease. The basis for this beneficial effect is unknown. Some patients with CD have bacterial overgrowth secondary to strictures, fistulas and hypomotility, and this may provide the basis for a portion of the symptomatic benefit achieved with some antibiotics. Metronidazole $400 \mathrm{mg}$ bid has effectiveness similar to that of sulfasalazine in active $\mathrm{CD}$ (75), and is useful for treating abscesses, fistulas and perianal lesions.

Pouchitis is a syndrome of unknown cause that develops specifically in patients operated on for UC (leaving them with an ileal pouch). Metronidazole has been used with satisfactory results in combination with antidiarrheal agents in the treatment of pouchitis (76). Also, enemas containing mesalamine have been shown to give satisfactory results in the treatment of pouchitis (77). The mechanism of action of these medications in treating pouchitis is unclear.

The results of using clofazimine $100 \mathrm{mg} /$ day administered with prednisone $45 \mathrm{mg} /$ day to 25 patients with active CD (78) have been compared with results of using prednisone alone. There was no added benefit for acute therapy, but when clofazimine was continued without prednisone for eight months, patients had fewer relapses than those maintained on placebo. This interesting and important possibility of the use of clofazimine for maintenance therapy in CD needs to be confirmed.

Rutgeerts and co-workers (79) tested the efficacy of fifabutin and ethambutol in combination for their ability to heal severe recurrent $C D$ at the neoterminal ileum. No patient who received treatment demonstrated improvement, either endoscopically or clinically.

In acute UC, adding oral tobramycin to the standard acute regimen may be of benefit (80), but the addition of tobramycin plus metronidazole to intravenous hydrocortisone is of no added benefit in patients with severe acute UC (81).

\section{GLUCOCORTICOSTEROIDS}

Intravenous: The outcome of medical treatment in patients with severe attacks of UC is worse than that in those with more extensive disease and with the early presence of gas in the small bowel $(82,83)$. An old and tried regimen of intravenous fluids, $60 \mathrm{mg} /$ day intravenous prednisolone, an antibiotic (tetracycline was initially used), and blood and electrolyte balance (84) is used for five to 10 days; the response rate is about two patients in three, with a mortality rate of about $1 \%$. Thus, the use of high dose intravenous GS for at least five days represented a major therapeutic step for patients with severe attacks of UC. The value of this protocol, which has been partially modified by excluding antibiotics and prolonging treatment for up to 10 days, has been confirmed more recently $(85,86)$. In an attempt to improve the outcome of patients with severe attacks of UC, GS were given as a pulse dosage of methylprednisolone $1 \mathrm{~g} /$ day for three days (87), followed by $100 \mathrm{mg}$ hydrocortisone every $6 \mathrm{~h}$ for two days together with topical GS treatment. The success rate was about $60 \%$, not different from that obtained in previous studies by the same group. The regimen followed for patients with severely active CD is usually the same as for UC patients, but controlled trials have not yet been done to prove the expected efficacy of this intensive regimen. 


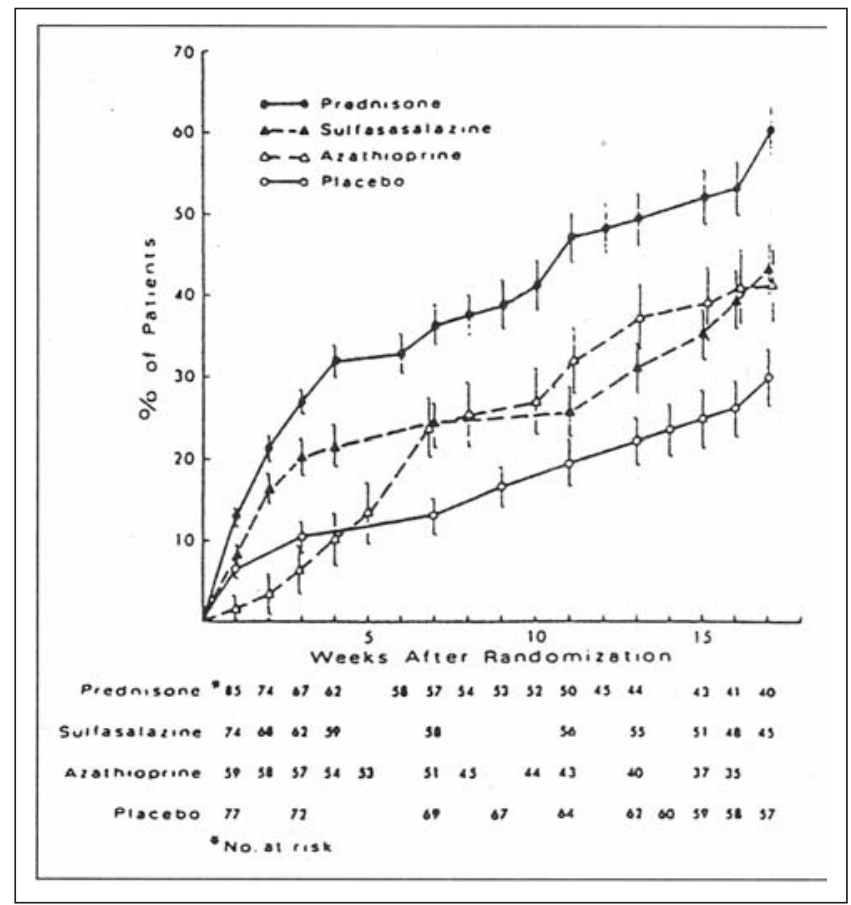

Figure 10A) Lifetable using Kaplan-Meier method showing cumulative percentage of patients in remission week by week. Remission is defined as Crohn's disease activity index less than 150 and continuing below 150 through week 17. Bars indicate SEM. Reproduced with permission from reference 7

What is to be done immediately for UC patients who do not respond to this intensive regimen? Correct timing for early surgery is paramount (88). The use of intravenous cyclosporine remains promising, but is at an early stage of development for possible use as adjunct therapy for persons with active UC not responding to intravenous GS (see the subsection Cyclosporine under Immunomodulators).

There is no widely accepted definition of refractory disease, either in terms of accepted dose and duration of treatment, or in terms of an acceptable outcome measure. A pragmatic approach to refractory distal UC has been published (85), but there are no scientific data on which approach is optimal, or on what constitutes disease refractory to oral or to intravenous therapy.

Oral: Orally administered GS act systemically and locally. The first used GS, prednisone and prednisolone, are systemically active. Prednisone 0.5 to $0.75 \mathrm{mg} / \mathrm{kg} /$ day orally is effective in treating moderately active $\mathrm{CD}$, as shown by the NCCDS (7) and by the European Cooperative Crohn's Disease Study (ECCDS) (8). GS work best in patients with ileal or ileocolonic disease, and when used in tapering doses over at least four months. The response of active symptomatic disease to prednisone or sulfasalazine was significantly better than that to placebo; the difference achieved with AZA was not statistically significant (7) (Figure 10). In the ECCDS (8), 6-methylprednisolone was the most effective drug in overall comparison in all patients (in previously treated patients and in those with small bowel or small bowel plus colonic disease). The combination of 6-methylprednisolone and

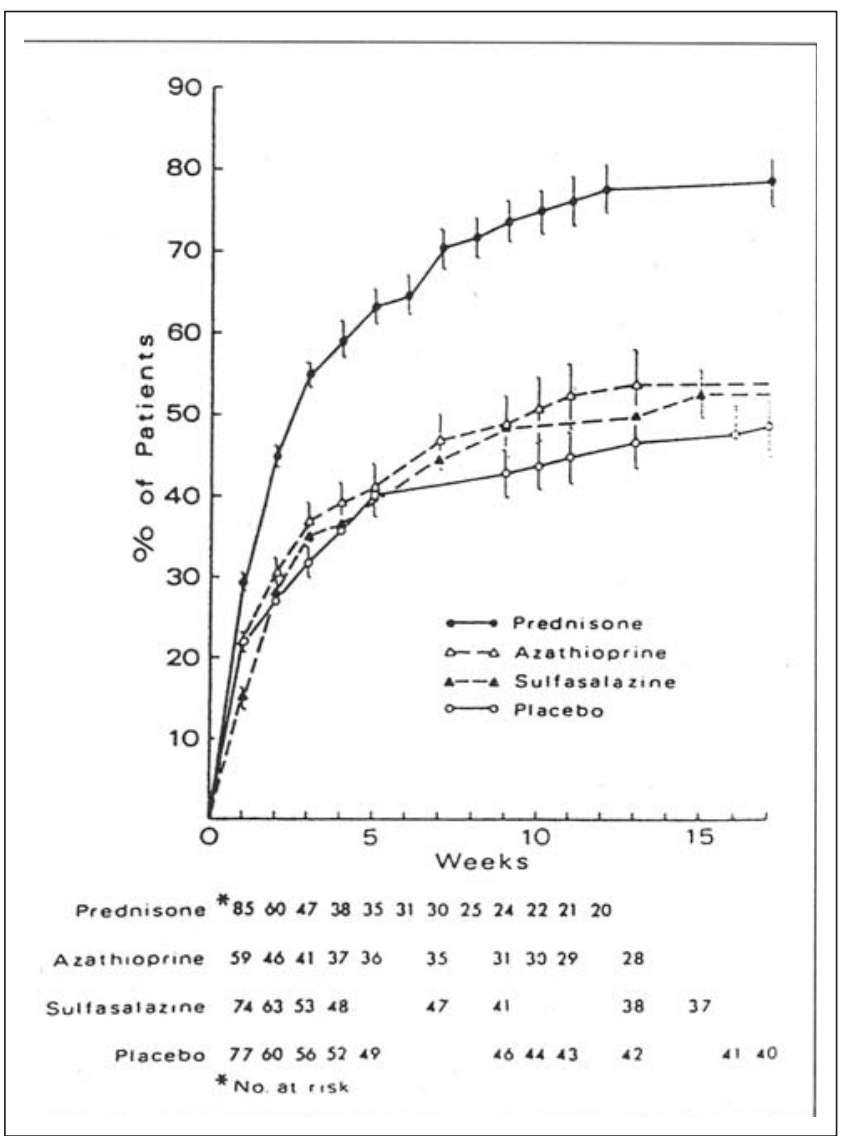

Figure 10B) Lifetable using Kaplan-Meier method showing mean Crohn's disease activity index week by week of patients in each treatment group who completed 17 weeks in the study. Bars give SEM. Reproduced with permission from reference 7

sulfasalazine was the most effective regimen in previously untreated patients and when disease was localized to the colon. In patients with colonic involvement, prednisone $1 \mathrm{mg} / \mathrm{kg} /$ day exerts only a minor benefit on colonic mucosal endoscopic biopsies, perhaps because of the transmural deepness of the lesions (89). Nonetheless, patients with moderately active colonic CD are usually not denied a trial of prednisone after the colonically active anti-inflammatory agents such as mesalamine have been tried and fail.

GS have mainly an effect on symptoms, without a clearly associated improvement in the inflammatory process; this statement is supported by results of two endoscopically controlled studies. In the first, Oliason et al (90) followed eight CD patients with recurrent preanastomatic ileal inflammation who received prednisolone 20 to $30 \mathrm{mg} /$ day for six to nine weeks. All patients showed clinical improvement, but endoscopic examination was unable to show objective evidence of decreased inflammation. Modigliani and associates (89) studied 142 patients with symptoms of active CD, increased erythrocyte sedimentation rates and colonoscopic signs of inflammation. Treatment comprised prednisolone $1 \mathrm{mg} / \mathrm{kg} /$ day for seven weeks, with symptomatic improvement in $63 \%$ of patients at four weeks and $92 \%$ at seven weeks. This clinical outcome was parallelled by a decrease in 
laboratory parameters suggesting biological activity, but only $29 \%$ of patients in clinical remission showed colonoscopic remission as well.

It is generally accepted that GS have no use for maintenance therapy in patients with $\mathrm{UC}$ or $\mathrm{CD}$, although the NCCDS showed that about a third of patients with active $\mathrm{CD}$ started on prednisone will need to remain on prednisone to suppress continued active disease. In the ECCDS (8), drug treatment was of no significant benefit to patients with quiescent disease, whereas continuous administration of low dose 6-methylprednisolone or 6-methylprednisolone plus sulfasalazine was beneficial in patients who responded initially to treatment of active disease. In a small group of patients with inactive CD (CDAI less than 150) but with abnormal laboratory parameters, GS used at a low dose $(0.25$ $\mathrm{mg} / \mathrm{kg} /$ day) for six months showed a reduced risk of clinical relapses compared with placebo $(91,92)$.

In a retrospective study, an alternate-day prednisone treatment regimen ( $25 \mathrm{mg}$ every other day) sustained clinical remission in $60 \%$ of 33 treated CD patients, with a mean follow-up of 6.6 years (93). There is difficulty in determining whether there is an active inflammatory process in patients with asymptomatic $\mathrm{CD}$ and whether maintenance therapy is really just lower dose suppressive therapy for lesser degrees of inflammation. These issues of defining continued active inflammation and whether suppression of this activity leads to a better prognosis need to be resolved before embarking on maintenance studies with newer therapeutic agents. It is necessary to determine whether the end-point of therapy should be improved clinical symptoms or improved laboratory measures, such as markers of increased intestinal permeability, $\mathrm{LTB}_{4}$ levels, immune markers or serum concentrations of acute phase reactants such as orosomucoid or C-reactive proteins.

There are two main categories of adverse effects seen with GS use: those related to withdrawal and those related to high dose treatment (94). There are numerous adverse effects from GS and, while these may be uncommon, they may be serious and/or unpleasant for the patient. For example, an increase in mean intraocular pressure (IOP) was reported when 109 young people (age seven to 21 years) with IBD were treated with oral prednisone for one to 104 months (95). There was no relationship between the IOP and the total prednisone dose, duration of treatment or number of days on high dose prednisone. The increased IOP fell in some patients when the dose of prednisone was decreased, but three persons had increased IOP while on only prednisone 5 $\mathrm{mg} /$ day.

Major research has been undertaken to develop rapidly metabolized GS, in an effort to limit availability of active GS components to inflamed intestinal tissue and, thus, to minimize the prevalence of GS side effects (95). Tixorcortol pivalate, beclomethasone and budesonide are examples of rapidly metabolized GS. These have been used as enemas or as tablets. Oral fluticasone proportionate $5 \mathrm{mg}$ qid is no better than placebo in the treatment of distal UC (96). A European (97) and a Canadian (98) study of over 475 patients with active $\mathrm{CD}$ proved the clinical efficacy of budesonide in an oral controlled ileal release formulation versus prednisolone or versus placebo, respectively. Adverse effects were much less prevalent with budesonide than with prednisone, and the suppression of the adrenal axis was also much less. Interestingly, some CD patients treated with placebo reported prednisone-associated adverse effects, such as moon face. In addition, oral budesonide $6 \mathrm{mg} /$ day for up to one year is significantly more efficacious than placebo in delaying relapse in ileocecal CD, with only minor systemic effects (99). This represents a potential breakthrough in the therapy of patients with IBD.

Topical - enemas and suppositories: Beclomethasone enemas $(0.5 \mathrm{mg} /$ day $)$ were compared with $5 \mathrm{mg}$ betamethasone enemas ( $5 \mathrm{mg} /$ day) for 28 days in 32 patients with acute UC (100). Both enema preparations were similarly effective, but beclomethasone diprophonate did not depress plasma cortisol levels (101). These results were confirmed in an Italian multicentre study of 44 patients using either budesonide ( $2 \mathrm{mg}$ in $100 \mathrm{~mL})$ or prednisolone $(20 \mathrm{mg} / 100 \mathrm{~mL})$ enemas for one month (102). Budesonide enemas are superior to placebo for the treatment of distal colitis or proctitis when given over a four-week period (103). In a multicentre Danish trial (104), 146 UC patients were given $100 \mathrm{~mL}$ enemas containing 1,2 or $4 \mathrm{mg}$ budesonide or $25 \mathrm{mg}$ prednisolone for two weeks; the $2 \mathrm{mg}$ dose was the most uniformly effective enema. Plasma cortisol levels did not change in the budesonide-treated patients. A Swedish group compared intrarectal budesonide 2 $\mathrm{mg} /$ day versus prednisolone $25 \mathrm{mg} /$ day in 100 patients with distal UC (105); the two treatments were similarly efficacious. Importantly, budesonide did not suppress plasma cortisol, as prednisolone did, and after eight weeks of treatment the decrease in S-osteocalcin was lower with budesonide than with prednisolone. Budesonide enemas have just been released for use in Canada.

Mesalamine enemas of 1 to $4 \mathrm{~g} /$ day are at least as effective as GS $(62,106,107)$. Mesalamine and 'new' steroid enemas were compared in a Dutch multicentre trial (108) in which patients received $2 \mathrm{mg} / 100 \mathrm{~mL}$ buclosamide or $4 \mathrm{~g} / 60 \mathrm{~mL}$ mesalamine for one month. Treatment outcomes were similar.

Oral versus topical treatment appears to be comparable in the treatment of distal UC, and the choice of one route versus another will depend on patient preference and will be influenced by the greater inconvenience and cost of topical versus oral therapy.

\section{IMMUNOMODULATORS}

AZA and 6-MP: The use of AZA and 6-MP in the treatment of patients with UC and CD has been reviewed (109). AZA and 6-MP in the treatment of $\mathrm{CD}$ patients are used either alone or in combination with GS. However, the use of these immunomodulators remains controversial (110-112). To ascertain whether AZA or 6-MP is effective in preventing disease relapse in patients with UC in remission, Hawthorne et al (113) conducted a one-year, placebo controlled, doubleblind trial of withdrawal of AZA in 79 patients who had been taking AZA for the previous six months and who had been in 
clinical remission for two months or more. Relapse rates of $36 \%$ in the AZA group and 59\% in the placebo group were found, which suggests that AZA maintenance treatment in UC patients is beneficial if patients have achieved remission while taking this drug. In a retrospective, 18-year study of 81 UC patients unresponsive to standard treatment it was possible to withdraw steroids in $48 \%$ of patients or to reduce them in $13 \%$ when patients were continued on $6-\mathrm{MP} 50 \mathrm{mg} /$ day (114). This suggests that AZA may represent useful maintenance therapy in selected patients with UC, but it is not clear why AZA rather than sulfasalazine or mesalamine would be used.

In a retrospective study of patients with resistant and steroid-dependent CD, the addition of AZA 1.5 to $2 \mathrm{mg} /$ $\mathrm{kg} /$ day (109) or 6-MP 50 to $70 \mathrm{mg} /$ day (115) may be useful. In another retrospective study with a mean follow-up of 1.6 years, data were obtained in 78 patients with extensive, refractory, complicated or steroid-dependent $\mathrm{CD}$, mainly with ileocolonic involvement (116). AZA (mean dosage $1 \mathrm{mg} /$ $\mathrm{kg} /$ day) and 6-MP controlled disease activity in 73\%, demonstrated a corticosteroid-sparing effect in $76 \%$ and reduced fistulization in $63 \%$. These results were usually evident after three to four months of therapy. About 10\% of the patients withdrew because of adverse effects.

Lemann et al (117) retrospectively analyzed the results obtained in 126 patients with CD who had been followed for up to 15 years while on AZA (three were on 6-MP): 109 had active $\mathrm{CD}$ at the beginning of the study, 63 were steroiddependent and 23 were steroid-resistant. After one year of treatment with AZA $2 \mathrm{mg} / \mathrm{kg} / \mathrm{day}$, 64\% were in remission, including $81 \%$ of those who had been in the steroiddependent group. In patients with quiescent $\mathrm{CD}$ at the start of the follow-up and treated with AZA, only $15 \%$ had a relapse after one year.

Other retrospective and uncontrolled studies have also supported the use of immunosuppressive agents in patients with refractory UC or CD $(118,119)$. For example, Verhave et al (120) used AZA $2 \mathrm{mg} / \mathrm{kg} /$ day in nine adolescents with $\mathrm{UC}$ and in 12 with CD who had relapsed during GS therapy, had severe side effects due to GS or had disease resistant to GS treatment. A full response was seen in six of nine UC and six of $12 \mathrm{CD}$ patients.

Several controlled trials of patients with chronic active $\mathrm{CD}$ in whom therapy with sulfasalazine or GS failed indicated that AZA/6-MP may help to achieve remission (121123). Other trials that included only a few patients with active CD did not report an advantage of AZA over placebo $(124,125)$. Recently, O'Brien et al (116) showed control of refractory disease, decreasing fistulization and steroidsparing in the majority of AZA-treated patients.

AZA may be a useful supplement to GS. Ewe and colleagues (126) reported on the effects of AZA $2.5 \mathrm{mg} / \mathrm{kg} / \mathrm{day}$ plus prednisolone versus prednisolone alone in 42 patients with active $C D$. Clinical activity was assessed by three different activity indexes: the CDAI (2), the Dutch or VHAI Index (127) and a severity-activity index (based on the data of the ECCDS [8]). All 42 patients received prednisolone 60

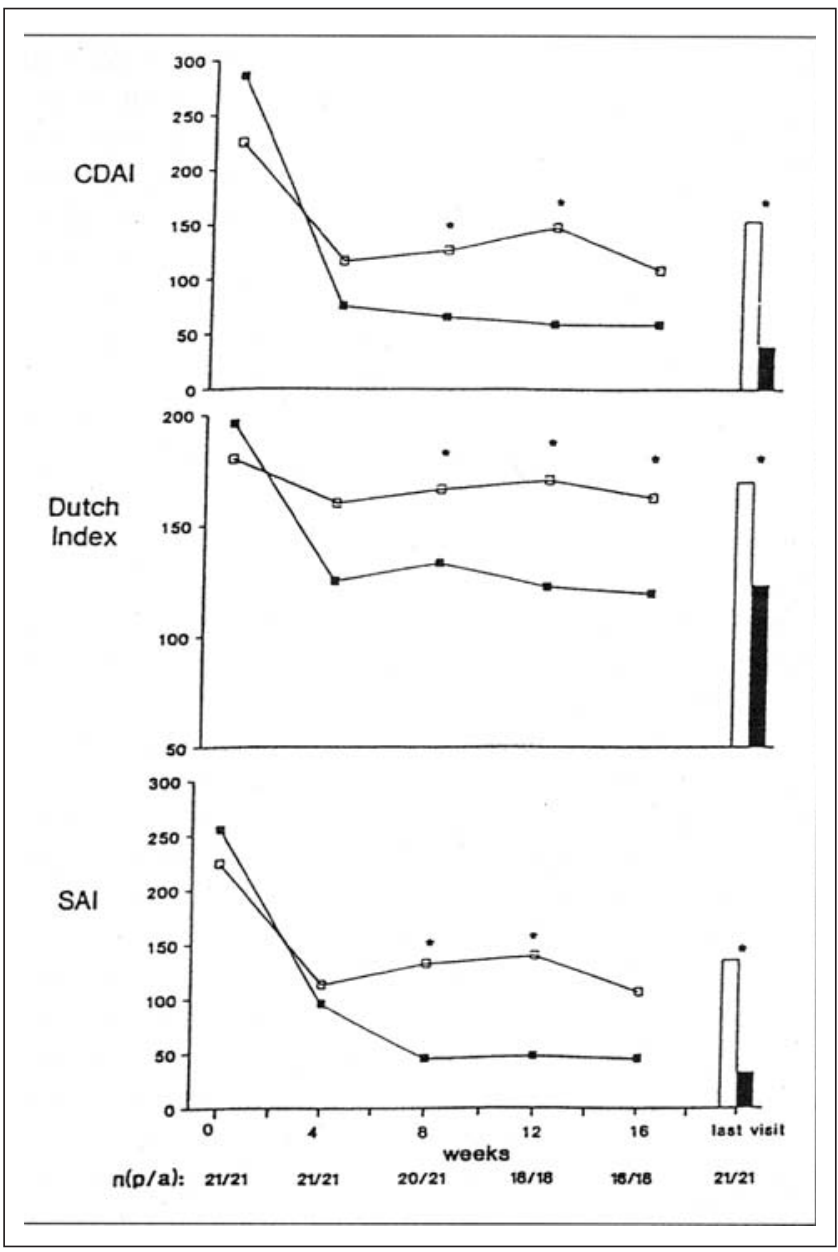

Figure 11) Median of activity indexes month by month in the azathioprine- $(a / \square)$ and placebo-treated $(p / \square)$ groups. Last visit, median of activity indexes (regular term or insufficient treatment) for Crohn's disease activity index (CDAI), Dutch index, and Self-Analysis Inventory (SAI). $* P<0.05$. Reproduced with permission from reference 10

$\mathrm{mg} /$ day tapering to a maintenance dosage of $10 \mathrm{mg} /$ day over seven weeks. In addition, half the patients took AZA 2.5 $\mathrm{mg} / \mathrm{kg} /$ day. After 16 weeks of treatment, $76 \%$ of patients on AZA plus prednisolone therapy, but only $38 \%$ of patients on prednisolone therapy, were in remission with a CDAI less than 150 . Two of the three activity indexes showed that the combination of AZA plus prednisolone was superior to prednisolone alone (Figure 11). The localization of CD did not substantially influence the proportions of treatment success or failure between the groups with one possible exception: all six patients with Crohn's colitis responded to the combined treatment versus only two of five patients who received prednisolone alone $(\mathrm{P}=0.061)$. In the AZA-treated group it was possible to taper the prednisolone dose according to the defined schedule in $57 \%$ of patients, whereas regular tapering of prednisolone in $\mathrm{CD}$ patients achieving remission on placebo occurred in only $24 \%$. Thus, the addition of AZA to prednisolone in patients with active CD had several advantages over treatment with prednisolone alone: remission was achieved more safely, more frequently, more 
quickly and with a lower total dose of prednisolone. Serious side effects were not recorded, and no patient on AZA had any evidence of bone marrow depression. Therefore, a recommendation to overlap GS therapy during the first months of treatment with AZA/6-MP can be derived from these observations.

Although the response to AZA in the NCCDS was better than the response to placebo, the difference did not reach conventional levels of statistical significance (7). However, the NCCDS study has been criticized because of the withdrawal of GS therapy in many patients just before the beginning of the trial $(110,112,128)$. This concern was obviated in the study by Ewe et al (126); 20 of the 42 patients had been on GS therapy four weeks before randomization. Also, regarding previous studies with AZA, a mean time of 3.1 months is needed for a clinical response (128), with $20 \%$ of patients requiring more than four months to respond to 6-MP. Other investigators have shown that the median time interval for patients with $\mathrm{CD}$ refractory to conventional treatment to respond to AZA is three months (116). Four studies have now shown the steroid-sparing effect of AZA $(116,122,126,128)$. A recent meta-analysis of eight randomized, double-blind, placebo controlled trials in active or quiescent CD demonstrated that $74 \%$ of patients responded, but usually after 16 weeks or longer (129). Steroids may be reduced to $5 \mathrm{mg}$ or less per day in $56 \%$ of patients treated with AZA but in only $18 \%$ of steroid-treated patients not receiving AZA. In these studies the odds ratio was 9.3 for AZA use in active disease, 1.7 in quiescent disease and 10.25 in patients with fistulas $\mathrm{CD}$, with $68 \%$ responding to AZA and only $12 \%$ to placebo.

These recently reconfirmed positive effects of AZA have to be balanced against its potential adverse effects. The most hazardous factor is bone marrow depression with white blood cell counts below $2.5 \times 10^{9} / \mathrm{L}$ being reported in $2 \%$ of patients during more than 20 years of experience with 6-MP (130). Bone marrow toxicity of AZA was higher in the short term treatment phase of the NCCDS (131). Two patients had to be withdrawn from this trial because of leukopenia, and 15\% of patients on AZA had total white blood cell counts of less than $4.0 \times 10^{9} / \mathrm{L}$, requiring AZA dose reduction. Recently, Connell et al (132) reported two deaths among 714 patients with IBD who were treated with AZA; both deaths were related to bone marrow aplasia. Furthermore, leukopenia was unpredictable and occurred at any time between zero and 132 months of treatment $(132,133)$. Other potentially serious AZA-associated complications include pancreatitis (134).

There may be genetic damage to the fetus with AZA (130). Nonetheless, it has been suggested that pregnancy in an IBD patient on AZA can be safely continued in those who initially conceived while being treated with this immunosuppressant (135). Many clinicians will remain cautious to continue AZA during pregnancy, despite this favourable suggestion.

Cyclosporine: Sandbom and Tremaine (136) discussed the utility of cyclosporine in patients with UC and CD. An ini- tial report on the use of cyclosporine in UC was not strongly encouraging (137). On the other hand, Hanauer et al (138) gave cyclosporine $4 \mathrm{mg} / \mathrm{kg} /$ day intravenously to 15 patients with severe UC not responding to intravenous hydrocortisone $300 \mathrm{mg} /$ day; $73 \%$ of these steroid-resistant patients showed clinical improvement within five to eight days. Cyclosporine was then continued orally (6 to $8 \mathrm{mg} / \mathrm{kg} /$ day), and at the end of six months six of 11 patients were off steroids and a further three had greatly reduced their daily GS dose. To avoid surgery in nonresponding UC patients, cyclosporine $4 \mathrm{mg} / \mathrm{kg} /$ day intravenously was given in an uncontrolled study; $70 \%$ of nonresponding UC patients were able to reduce their GS doses progressively (139). In a randomized, double-blind, controlled trial in which cyclosporine 4 $\mathrm{mg} / \mathrm{kg} /$ day or placebo was administered by continuous intravenous infusion to 20 patients with severe UC whose condition had not improved after at least seven days of intravenous corticosteroid therapy, $82 \%$ treated with cyclosporine improved, compared with those who received placebo (140).

Cyclosporine 5 to $7 \mathrm{mg} / \mathrm{kg} /$ day intravenously was used in a three-month, placebo controlled trial in patients with active $\mathrm{CD}$; after only two weeks there was "a significant improvement in active CD without a dramatic change in CDAI" (141). A progressive decrease in cyclosporine dose was associated with an increased relapse rate when these patients were seen in follow-up (142), similar to that happened when lower dosages ( $2 \mathrm{mg} / \mathrm{kg} /$ day $)$ were used to prevent the onset of nephrotoxicity (143). Two recently reported uncontrolled preliminary reports suggested a possible role for intravenous cyclosporine in patients with severely active CD $(144,145)$.

In a controlled trial of oral cyclosporine performed for treatment of active CD (146) 71 patients with active CD of the terminal ileum, colon or both were randomly assigned to either oral placebo or cyclosporine 5 to $7.5 \mathrm{mg} / \mathrm{kg} /$ day for three months. A total of $59 \%$ of the cyclosporine group responded, compared with $32 \%$ of the placebo-treated group. The response to cyclosporine was rapid, usually within two weeks. This is in marked contrast to the relatively slow response to AZA. Thus, oral or intravenous cyclosporine may have a role in the management of some patients with active CD.

In a carefully performed, Canadian, placebo controlled, clinical trial, cyclosporine $4.8 \mathrm{mg} / \mathrm{kg}$ was shown to be ineffective to maintain remission in $\mathrm{CD}$ as judged by the value of the CDAI or by QOL measures (147). In fact, more patients worsened on cyclosporine compared with placebo.

Sandborn et al (148) examined colonic tissue concentrations of cyclosporine in two children with severe UC. Colonic tissue concentrations of cyclosporine were higher in one patient responding to treatment, compared with the patient who did not respond. This suggests that varying tissue levels of cyclosporine may be one factor explaining the variable response to this drug, and raises the possibility that the administered oral dose of cyclosporine may not be adequate to achieve the desired clinical response in some patients (146).

There have been four uncontrolled studies evaluating the 
use of cyclosporine enemas for refractory proctosigmoiditis (149-152). In one study (152), 21 of 36 patients (58\%) responded to initial therapy, with 13 of 36 patients $(36 \%)$ remaining in remission after therapy was discontinued. Thus, there may be some role for cyclosporine enemas in patients with refractory distal colitis.

Methotrexate: Methotrexate has been proposed for use in patients with so-called refractory $\mathrm{CD}$ or UC. In an open study a weekly dose of methotrexate $25 \mathrm{mg}$ intramuscularly provided a favourable response (153). A further study showed the benefit of methotrexate in the treatment of $\mathrm{CD}$ patients refractory to AZA or 6-MP (154). A Canadian, double-blind study of methotrexate in patients with acute CD suggested that the addition of methotrexate to prednisone is superior to prednisone alone in patients with refractory active $\mathrm{CD}$ (155). The role of methotrexate as maintenance therapy in $\mathrm{CD}$ is under study.

Immunoglobulin and K-76: Intravenous immunoglobulin therapy has been used for active, extensive and medically refractory idiopathic UC or CD (156). Twelve young people with active UC not responding to sulfasalazine and/or GS received intravenous immunoglobulin $2 \mathrm{~g}$ /day during the induction phase, followed by 200 to $500 \mathrm{mg} / \mathrm{kg}$ every two weeks for 12 weeks. Six of the 12 UC patients were age one to 17 years. Six of the 12 patients completed 12 or more weeks of therapy, and five of these six enjoyed an improvement in colitis activity and had a significant reduction in their prednisone dose.

K-76, a monocarboxylic acid derivative of a culture supernatant of a fungus (Stachybotrys complementi), is a complement inhibitor that has been used in 21 patients with UC not responding to sulfasalazine or to GS (157) - 40\% showed improvement with addition of $\mathrm{K}-76$.

Other immunomodulators: Fusidic acid is an antibiotic with $\mathrm{T}$ cell-specific immunosuppressive effects. Five of eight patients with chronically active and medically resistant CD treated for eight weeks improved (158).

An interleukin-1 receptor antagonist compound has been shown to be useful in a rabbit immune colitis model (159). Open trials with chimeric monoclonal anti-CD4 antibody have suggested efficacy in a small number of patients with CD or UC (160).

An open trial of $\mathrm{T}$ cell apheresis demonstrated remission achieved in 64 of 72 patients with chronically active CD (161); remission was long-lasting. In contrast, in a later controlled trial, T cell apheresis allowed GS doses to be tapered, but relapse rates did not change (162).

\section{ENTERAL AND PARENTERAL NUTRITION}

Nutritional deficiencies are common in patients with IBD, especially in those with CD. Replacement of established deficiencies is important, and management of the 'at risk' patient is an important consideration. Nutritional therapy has been suggested to have a primary rather than an adjunctive role in the management of IBD patients (163). This topic has been carefully reviewed (164) (a full discussion of this topic is beyond the scope of this paper). Sitzmann and

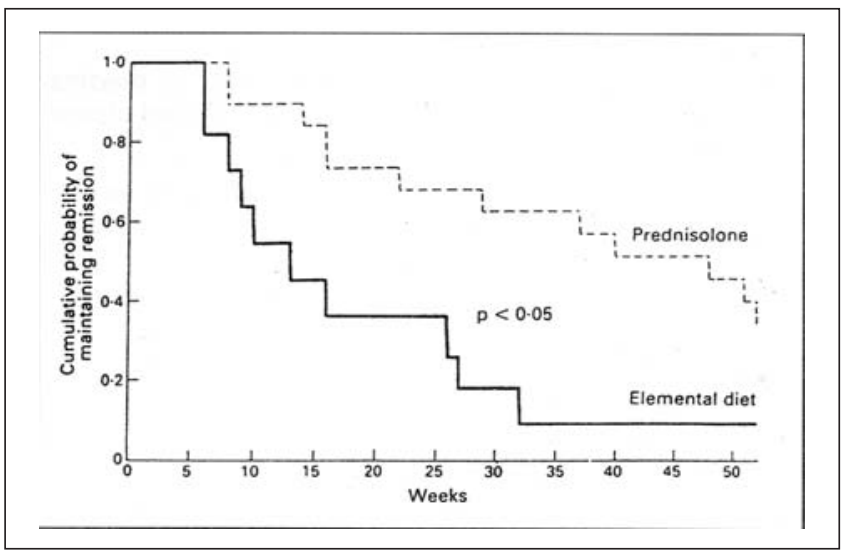

Figure 12) Cumulative probability of maintaining remission during one-year follow-up after treatment with prednisolone or elemental diet. Reproduced with permission from reference 172

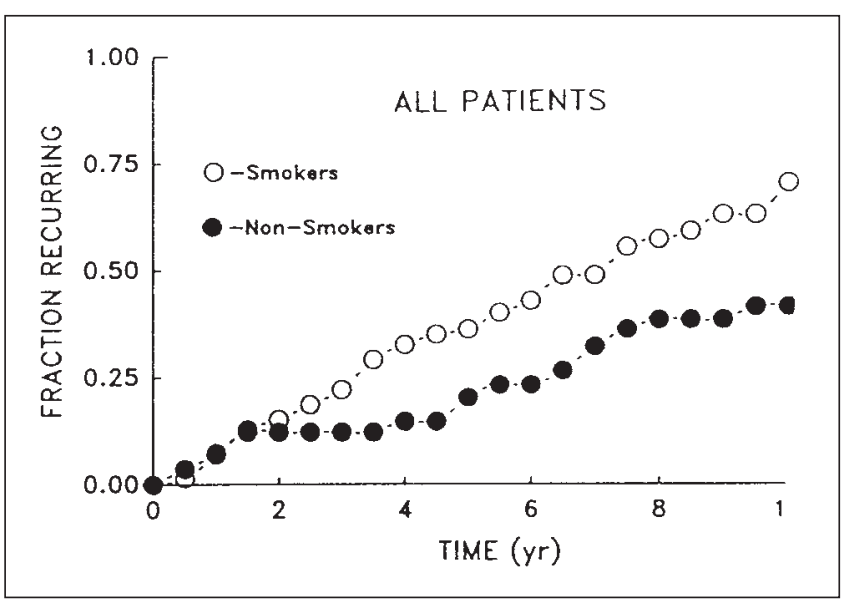

Figure 13) Five-and 10-year cumulative recurrence rates for smokers (36\%, 70\%) compared with nonsmokers (29\%, 41\%) (P=0.007). Difference between the two groups at five years was $16 \%(95 \% \mathrm{CI}=$ 2.4-29.6). At 10 years, the difference was 39\% (95\% CI = 14-54). Reproduced with permission from reference 177

co-workers (165) retrospectively reported the course of 22 patients with severe UC and 16 with Crohn's colitis treated with GS plus total parenteral nutrition (TPN). Seventeen UC patients required colectomy, whereas 15 of the 16 patients with CD entered remission. Thus, TPN may have a role in the primary management of patients with $\mathrm{CD}$ and not in those with UC. Home TPN for patients with short bowel syndrome improves the CD patient's nutritional status and their QOL, and decreases the need for intense medical treatment; disappointingly, home TPN does not affect the patient's need for hospitalization or surgery (27). TPN use has been recommended only for patients with severe illness, either with obstruction or with the short bowel syndrome $(165,166)$.

Enteral nutrition with an elemental diet is as effective as TPN in the treatment of IBD (167). A number of studies have suggested the benefit of enteral nutrition for the CD patient. For example, Teahon et al (168) assessed retrospec- 
TABLE 1

Publicly quoted cost of a one-month supply of medications used to treat patients with active or remitted ulcerative colitis and Crohn's disease

\begin{tabular}{|c|c|c|}
\hline & $\begin{array}{l}\text { Representa- } \\
\text { tive dose }\end{array}$ & $\begin{array}{l}\text { Cost per } \\
\text { month }\end{array}$ \\
\hline \multicolumn{3}{|l|}{ Anti-inflammatories } \\
\hline Sulfasalazine & 4 g/day & $\$ 54.38$ \\
\hline \multicolumn{3}{|l|}{ Mesalamine tablets } \\
\hline Dipentum (Pharmacia Upjohn) & 2 g/day* & $\$ 134.14$ \\
\hline $\begin{array}{l}\text { Asacol (Procter \& Gamble } \\
\text { Pharmaceuticals) }\end{array}$ & 2 g/day* & $\$ 87.06$ \\
\hline Mesasal (SmithKline Beecham) & 2 g/day* & $\$ 76.79$ \\
\hline Salofalk (Axcan Pharma) & 2 g/day* & $\$ 74.36$ \\
\hline $\begin{array}{l}\text { Pentasa (Hoechst-Marion- } \\
\text { Roussel) }\end{array}$ & 2 g/day* & $\$ 80.66$ \\
\hline Salofalk enemas & $1 /$ day ( 4 boxes) & $\$ 192.81$ \\
\hline Salofalk suppositories & 250 mg/day & $\$ 32.93$ \\
\hline \multicolumn{3}{|l|}{ Antibiotics } \\
\hline Metronidazole & 1000 mg/day* & $\begin{array}{l}\$ 11.33 \\
\text { (generic) }\end{array}$ \\
\hline \multicolumn{3}{|l|}{ Glucocorticosteroid tablets } \\
\hline Deltasone (Pharmacia Upjohn) & $20^{*}$ & $\$ 7.84$ \\
\hline $\begin{array}{l}\text { Betnesol enemas (Roberts } \\
\quad \text { Pharmaceutical Canada, Inc) }\end{array}$ & $\begin{array}{l}1 \mathrm{~g} / \mathrm{h} \text { (one box } \\
\text { containing } \\
7 \text { enemas) }\end{array}$ & $\begin{array}{l}\$ 16.09 \text { or } \\
\$ 48.00 / \\
5 \text { boxes }\end{array}$ \\
\hline Cortifoam (Reed \& Carnrick) & $1 \mathrm{~g} / \mathrm{h}(20 \mathrm{~g})$ & $\$ 85.75$ \\
\hline \multicolumn{3}{|l|}{ Immunomodulators } \\
\hline Azathioprine & 150 mg/day & $\$ 92.45$ \\
\hline Cyclosporine & 600 mg/day* & $\$ 1,090.09$ \\
\hline Methotrexate & 25 mg/day* & $\$ 181.32$ \\
\hline \multicolumn{3}{|l|}{ Nutrition ${ }^{\dagger}$} \\
\hline Parenteral & As needed & 250/day \\
\hline Ensure (Abbott Laboratories Limited) & 2/day & $\$ 1.98 / \mathrm{can}^{\ddagger}$ \\
\hline Boost (McNeil Pharmaceutical) & 2/day & $\$ 1.68 / \mathrm{can}^{\S}$ \\
\hline \multicolumn{3}{|l|}{ Antidiarrheal agents } \\
\hline Lomotil (Searle Canada Inc) & $\begin{array}{l}20 \mathrm{mg} / \mathrm{day} \\
(8 \times 30)\end{array}$ & $\$ 120.88$ \\
\hline $\begin{array}{l}\text { Imodium (Janssen } \\
\quad \text { Pharmaceutica Inc) }\end{array}$ & $\begin{array}{l}16 \mathrm{mg} / \mathrm{day} \\
(8 \times 30)\end{array}$ & $\$ 156.60$ \\
\hline Codeine & $\begin{array}{c}60 \mathrm{mg} / \mathrm{day} \\
(2 \times 30)\end{array}$ & $\$ 14.73$ \\
\hline $\begin{array}{l}\text { Questran (Bristol-Myers Squibb } \\
\text { Canada Inc) }\end{array}$ & 8 g/day & $\begin{array}{l}\$ 40.79 / 21- \\
\text { day supply }\end{array}$ \\
\hline
\end{tabular}

${ }^{*} T h e$ dose may vary from patient to patient, and at different times. The doses shown here are representative. The costs represent a mean of two values quoted from a telephone survey conducted in Edmonton in March 1994; ${ }^{\dagger}$ The cost of these preparations varies widely. For example, the cost of total parenteral nutrition (TPN) depends on whether the direct or the direct plus indirect costs are included. The figure of \$250/day for TPN is considered to be a conservative estimate. There are numerous appropriate nutritional supplements that may benefit patients with inflammatory bowel disease, and these range widely in price. The monthly estimates were based on the use of 2 units/day, and a 30 -day month; ${ }^{\ddagger} \$ 21.88 /$ case; $\$ \$ 9.98 / 6$ cans

tively the short and the long term outcomes of 113 patients with CD who were treated primarily with an elemental diet. Remission was obtained in $85 \%$ of patients after four weeks. At follow-up at least five years after elemental diet use, the annual relapse rate was less than 10\%. Giaffer et al (169) treated 30 patients with active $C D$ with either an elemental diet or a polymeric supplement containing intact protein. After 10 days, 12 of 16 patients (75\%) on the elemental diet improved, compared with five of 14 (36\%) on the polymeric diet.

It is controversial whether enteral nutrition can modify the long term course of CD $(169,170)$. In a large and welldesigned multicentre study enrolling 107 patients with active $\mathrm{CD}$ randomized to receive only enteral nutrition with a liquid oligopeptide diet or 6-methylprednisolone $48 \mathrm{mg} /$ day plus sulfasalazine $3 \mathrm{~g} /$ day, a higher proportion of patients treated with these two drugs were in remission (41 of 52, $79 \%)$ after six weeks compared with those treated with enteral nutrition ( 29 of 55, 53\%) (171). In contrast, in 42 patients with active CD treated with prednisolone or Vivonex TEN (Sandoz Nutrition Corporation) for four weeks, elemental diet was as effective in the short term as prednisolone in newly and previously diagnosed CD patients, and the benefit of this elemental diet was independent of the patient's nutritional status (172). The subsequent relapse after elemental diet-induced remission, however, is greater than after treatment with GS (Figure 12).

Enteral nutrition can restore the increased intestinal permeability in CD to normal (173). The significance of this observation is unknown.

Are there specific nutrients ('gut fuels', such as short chain fatty acids or glutamate) that may be beneficial when added to the diet or to enteral supplements? Butyrate is the major energy-yielding substrate for colonocytes, and sodium butyrate in the form of enemas $100 \mathrm{mM}$ has been used in single-blind randomized crossover study in 10 patients with distal UC unresponsive to standard therapy (174). Compared with placebo enemas, sodium butyrate enemas were effective. Senagore et al (175) compared short-chain fatty acid enemas (sodium acetate $60 \mathrm{mM}$, sodium butyrate $40 \mathrm{mM}$ and sodium propionate $30 \mathrm{mM}$ ) with hydrocortisone enemas $(100 \mathrm{mg} / 60 \mathrm{~mL})$ or mesalamine enemas $(4 \mathrm{~g} / 60 \mathrm{~mL}$ bid) in patients with nonspecific proctosigmoiditis; they found no difference in response rates. This suggests that short-chain fatty acid enemas may be useful treatment for some patients with distal UC. These enemas are not yet commercially available, but may prove to be cheaper than 5-ASA- or GScontaining preparations. One pragmatic drawback for the widespread use of butyrate enemas is their foul odour (176).

\section{LIFESTYLE MODIFICATION}

Smoking may worsen the clinical course of patients with CD (Figure 13), yet symptoms in smoking patients with UC may worsen when they give up that habit (177). Nicotine chewing gum does not benefit the clinical course of UC patients (178). To date, no controlled clinical trial has specifically stratified for smoking before patients were randomized; outcome results with budesonide appear to be similar in smokers versus nonsmokers $(97,98)$. There is anecdotal evidence from controlled trials in UC for clinical improvement with transdermal nicotine (179).

Inhibition of cyclooxygenase by the use of NSAIDs is associated with colitis flaring in some patients, and there is 
clear evidence for the existence of NSAID-induced colitis in adults (180). Exacerbation of colitis by NSAIDs in rats is not related to elevated LTB4 levels, but is due instead to inhibition of cyclooxygenase products. Peripheral and axial arthralgias are common in patients with IBD, and these symptoms are treated with management of the associated IBD, physiotherapy and judicious use of acetaminophen. Oral contraceptive use may be a risk factor for the development of IBD, even after correcting for the adverse effect of smoking (personal communication).

\section{OTHER AGENTS}

Lidocaine (181) or bismuth subsalicylate (182) enemas appear to be of some promise, as assessed in open studies. Clearly, these need to be validated in controlled clinical trials. There has been limited experience reported with sucralfate in patients with IBD (183). Verapamil inhibits the release of LTB4 from the rectal mucosa of patients with active UC (184); its clinical efficacy is unknown. An organic arsenical acetarsol (an experimental drug not available for prescription in Canada) has been found to be at least as effective as suppositories of prednisolone-21-phosphate (185). A controlled clinical trial has been launched using tumour necrosis factor-alpha. Interferon has been examined in open studies, and controlled clinical trials are soon to be initiated.

Hydroxychloroquine (Plaquenil; Sanofi Winthrop) $400 \mathrm{mg} /$ day has been used in a placebo controlled trial, with no beneficial results noted (186), in contrast to the early positive suggestion from an open trial in refractory UC (187).

\section{SOCIAL CONSCIENCE: WHAT IS THE COST?}

CD and UC impair QOL, potentially affect income, and increase hospitalization and difficulty obtaining life insurance coverage (even though the mortality rate of UC and $\mathrm{CD}$ patients is no different now from that of an otherwise healthy community) (188). This pain and suffering is difficult to quantify on a strictly dollar basis. Careful cost analysis

\section{REFERENCES}

1. Gastroenterology 1990;99:956-63.

2. Gastroenterology 1979;77:843-6.

3. J Clin Gastroenterol 1991;13:5-7.

4. Dig Dis Sci 1992;37;801-12.

5. Ann Intern Med 1993;118:540.

6. Gut $1973 ; 14: 923$.

7. Gastroenterology 1979;77:847-69.

8. Gastroenterology 1984;86:249-66.

9. Gastroenterology 1976;70:439-44.

10. Ann Intern Med 1991;114:445-50.

11. Aliment Pharmacol Ther 1993;7:369-83.

12. Q J Med 1990;278:551-62.

13. Aliment Pharmacol Ther 1991;5:449-70.

14. Gut 1992;33:252-55.

15. Am J Gastroenterol 1992;87:438-42.

16. Lancet 1992;340:1468.

17. Lancet 1992;339:1279-81.

18. Postgrad Med J 1992;68:189-91.

19. Aliment Pharmacol Ther 1992;6:479-85.

20. Aliment Pharmacol Ther 1992;6:647-52.

21. Clin Inv Med 1993;16:B46.

22. Aliment Pharmacol Ther 1990;4:55-64.

23. N Engl J Med 1986;317:1625-9.

24. Eur J Gastroenterol Hepatol 1990;2:229.

25. Ann Intern Med 1991;115:350-5. of IBD medical therapy has not yet been formally completed, but sulfasalazine maintenance therapy in patients with UC results in a fall in the expected annual rate of relapse from approximately $80 \%$ to $20 \%$. In $\mathrm{CD}$, the annual risk of recurrence falls from approximately $50 \%$ to $25 \%$ with the use of mesalamine. When viewing strictly the cost of medications, there is considerable variation in the monthly expenditures for sulfasalazine tablets, enemas or suppositories of sulfasalazine, mesalamines or GS (Table 1).

While GS is relatively inexpensive, potential adverse effects dissuade its use for first-time or initial therapy. While sulfasalazine is as effective as the newer 5-ASA compounds and is somewhat cheaper in price, there is the concern about the much higher prevalence of adverse effects. This provides the rationale basis, therefore, for the suggestion to begin all newly diagnosed patients with mild to moderately active CD or UC on one of the cost-effective formulations of mesalamine, in doses of at least $3 \mathrm{~g} /$ day (Figure 10). If eight weeks of therapy are ineffective to achieve a remission, then it will be necessary to add prednisone, approximately $40 \mathrm{mg} /$ day. If after a further eight weeks the patient continues to be unwell, then the addition of intravenous/oral cyclosporine or AZA needs to be contemplated and judicious timing of surgery considered.

ACKNOWLEDGEMENTS: I thank Drs R McLeod, F Martin, L Sutherland and N Williams for asking me to participate in the discussion of newer therapies in patients with inflammatory bowel disease, and to submit this manuscript for critical peer review. The permission by Dr L Sutherland to use Figures 5 to 8 is acknowledged with gratitude. The secretarial and word processing assistance of Trudi Schmidt and Marlene Hoffmann is gratefully acknowledged. I also thank Mrs Peggy Kirdeikis for performing the telephone survey of the cost of medications used in Table 1.

DEDICATION: This work is dedicated to the memory of Grace and Arthur Lewis.

26. Gut 1991;32:183-7.

27. Am J Gastroenterol 1990;85:562-6.

28. Gut 1992;33:252-5.

29. Gastroenterology 1982;83:1062-71.

30. Br J Clin Pharmacol 1991;32:248-50.

31. Gut 1990;31:1271-6.

32. Aliment Pharmacol Ther 1990;4:523-33.

33. Gut 1992;33:1338-42.

34. Scand J Gastroenterol 1989;24:1179-85.

35. Gastroenterology 1993;104:1293-1300.

36. Digestion 1990;45:88-92.

37. Can J Gastroenterol 1990;4:452-7.

38. Gastroenterology 1990;98:811-8.

39. Scand J Gastroenterol 1991;26(Suppl 183):68.

40. Am J Gastroenterol 1993;88:1343.

41. Gastroenterology 1992;103:363-8.

42. Dig Dis Sci 1992;37:29-32.

43. Aliment Pharmacol Ther 1994;8:35-43.

44. Trends in Inflammatory Bowel Disease Therapy, Victoria, April 6-9, 1994.

45. Gastroenterology 1992:103:694-704

46. Am J Gastroenterol 1994;89:692-8.

47. Dig Dis Sci 1990;35:1180-2.

48. Can Med Assoc J 1990;143:1031-2.

49. Gastroenterology 1988;95:1449-53.

50. Aliment Pharmacol Ther 1988;2:237-43. 
51. Gastroenterology 1988;94:1383-9.

52. Gut 1988;29:835-7.

53. Gastroenterology 1986;90:1024-30.

54. Gastroenterology 1993;105:1057-60.

55. Ann Intern Med 1991;114:445-50.

56. Gastroenterology 1991;101:1130-1. (Edit)

57. Scand J Gastroenterol 1990;25:663-8.

58. Scand J Gastroenterol 1990;25(Suppl 172):63-5.

59. Int J Colorectal Dis 1990;5:79-81.

60. Gastroenterology 1991;100:A200.

61. Gut 1991;32:929-31.

62. Am J Surg 1992;164:85-9.

63. Trends in Inflammatory Bowel Disease Therapy, Victoria, April 6-9, 1994, poster 21.

64. Lancet 1981;ii:270-1.

65. Gastroenterology 1990;99:113-8.

66. Scand J Gastroenterol 1990;25(Suppl 172):60-2.

67. Am J Gastroenterol 1990;85:1079-82.

68. Am J Gastroenterol 1992;87:342-6.

69. Gastroenterology 1991;100:A253.

70. Ann lntern Med 1992;116:609-14.

71. Am J Gastroenterol 1992;87:432-7.

72. J Belge Radiol 1991;74:115-6.

73. Gut 1992;33:922-8.

74. Gut 1991;32:1071-5.

75. Gastroenterology 1982;83:550-62.

76. Int J Colon Dis 1988;3:226-8.

77. N Engl J Med 1989;320:257.

78. Dig Dis Sci 1991;36:449-53.

79. J Clin Gastroenterol 1992;15:24-8.

80. Aliment Pharmacol Ther 1990;4:123-9.

81. Dis Colon Rectum 1994;37:58-62.

82. Lancet 1974;i:1067-70.

83. Lancet $1974 ; \mathrm{i}: 1086-8$.

84. Lancet 1974;i;1067-70.

85. Gastroenterol Int 1991;4:93-8.

86. Gastroenterology 1985;89:1005-13.

87. J Clin Gastroenterol 1990;12:40-1.

88. Gastroenterol lnt 1991;4:161-64.

89. Gastroenterology 1990;98:811-8.

90. Gut 1990;31:325-28.

91. Gastroenterology 1986;91:1490-4.

92. J Clin Gastroenterol 1988;10:631-4.

93. Am J Gastroenterol 1991;86:460-6.

94. Dis Colon Rectum 1992;35:1003-9.

95. Gastroenterology 1992;102:1957-61.

96. Gut 1992;33:711-4.

97. Gastroenterology 1993;104A:772.

98. Gastroenterology 1993;105:1057-60.

99. Gastroenterology 1994;106:A722.

100. J Clin Gastroenterol 1991;13:38-41.

101. Scand J Gastroenterof 1987;22:987-92.

102. Ital J Gastroenterol 1991;23:640.

103. Scand J Gastroenterol 1992;27:9-12.

104. Scand J Gastroenterol 1991;26:1225-30.

105. Gut 1993;34(Suppl):41.

106. Lancet 1977;ii:892-5.

107. Dig Dis Sci 1987;2:598-602.

108. Am J Gastroenterol 1991;100:A223.

109. Gastroenterol Clin North Am 1989;18:57-71.

110. Dig Dis Sci 1981;26:364-8.

111. Dig Dis Sci 1981;26:368-71.

112. Gastroenterology 1981;80:193-200.

113. BMJ 1992;305:20-2.

114. Am J Gastroenterol 1990;85:717-22.

115. Mayo Clin Proc 1991;66:480-4.

116. Gastroenterology 1991;101:3946.

117. Gastroenterol Clin Biol 1990;14:548-54.

118. J Clin Gastroenterol 1990;12:271-5.

119. Dis Colon Rectum 1990;33:374-7.

120. J Pediatr 1990;117:809-14.
121. Lancet 1971;ii:944-7.

122. A J Dig Dis 1975;20:721-6.

123. Lancet 1978;ii:955-7.

124. Lancet 1971;ii:1273-6.

125. Gastroenterology 1974;66:916-22.

126. Gastroenterology 1993;105:367-72.

127. Gut 1980;21:279-86.

128. N Engl J Med 1980;302:981-7.

129. Trends in Inflammatory Bowel Disease Therapy, Victoria, April 6-9, 1994 , poster 8.

130. Ann Intern Med 1989;111:641-9.

131. Gastroenterology 1979;77:870-82.

132. Gut 1992;33(Suppl 1):S10. (Abst)

133. Gut 1993;34:1081-5.

134. Gastroenterology 1979;77:883-6.

135. Gastroenterology 1990;99:443-6.

136. Mayo Clin Proc 1992;67:981-90.

137. Aliment Pharmacol Ther 1989;3:143-9.

138. Gastroenterology 1990;98:A174.

139. Lancet 1990;336:16-9.

140. N Engl J Med 1994;330:1841-5.

141. N Engl J Med 1989;321:845-50.

142. Scand J Gastroenterol 1991;26:689-95.

143. J Clin Gastroenterol 1991;13:42-5.

144. Trends in Inflammatory Bowel Disease Therapy, Victoria, April 6-9, 1994, poster 16

145. Trends in Inflammatory Bowel Disease Therapy, Victoria, April 6-9, 1994, poster 33.

146. Scand J Gastroenterol 1992;27:961-7.

147. N Engl J Med 1994;330:1846-51.

148. J Pediatr Gastroenterol Nutr 1992;15:125-9.

149. Lancet 1989;i:721-2.

150. Lancet 1989;ii:97.

151. Gastroenterology 1990;98:A202.

152. Am J Gastroenterol 1993;88:640-5.

153. Ann Intern Med 1989;110:353-6.

154. Gastroenterology 1991;100:A222.

155. N Engl J Med 1995;332:292-7.

156. Am J Gastroenterol 1992;87:91-100.

157. Dis Colon Rectum 1992;35:560-7.

158. Aliment Pharmacol Ther 1992;6:495-502.

159. Gastroenterology 1992;103:65-71.

160. Gastorenterology 1992;102:A615.

161. Digestion 1979;19:197-201.

162. J Clin Gastroenterol 1989;11:136-8.

163. Scand J Gastroenterol 1990;25(Suppl 172):29-34.

164. J Pediatr Gastroenterol Nutr 1993;17:247-54.

165. Gastroenterology 1990;99:1647-52.

166. Am J Surg 1990;159:540-5.

167. Am J Gastroenterol 1991;86:317-21.

168. Gut 1990;31:1133-7.

169. Lancet 1990;335:816-9.

170. Gut 1991;32:1492-7.

171. Gastroenterology 1991;101:881-8.

172. Gut 1993;34:1198-1202.

173. Gastroenterology 1991;101:84-9.

174. Gastroenterology 1992;103:51-6.

175. Dis Colon Rectum 1992;35:923-7.

176. Falk Symposium Foundation, Freiburg, Germany, 1990:45.

177. Gastroenterology 1990;98:1123-8.

178. Dig Dis Sci 1990;35:827-32.

179. Gastroenterology 1991;100:A252.

180. Arch Intern Med 1992;152:625-32.

181. Gastroenterology 1991;100:A198.

182. Aliment Pharmacol Ther 1990;4:333-8.

183. Gastroenterology 1992;102:A714.

184. Aliment Pharmacol Ther 1992;6:163-8.

185. Lancet 1965;i:238-9.

186. Gastroenterology 1992;102:A661.

187. Gastroenterology 1988;984:A293.

188. Can J Gastroenterol 1994;8:438-45. 


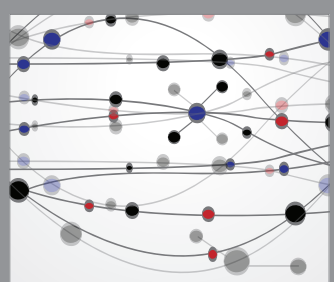

The Scientific World Journal
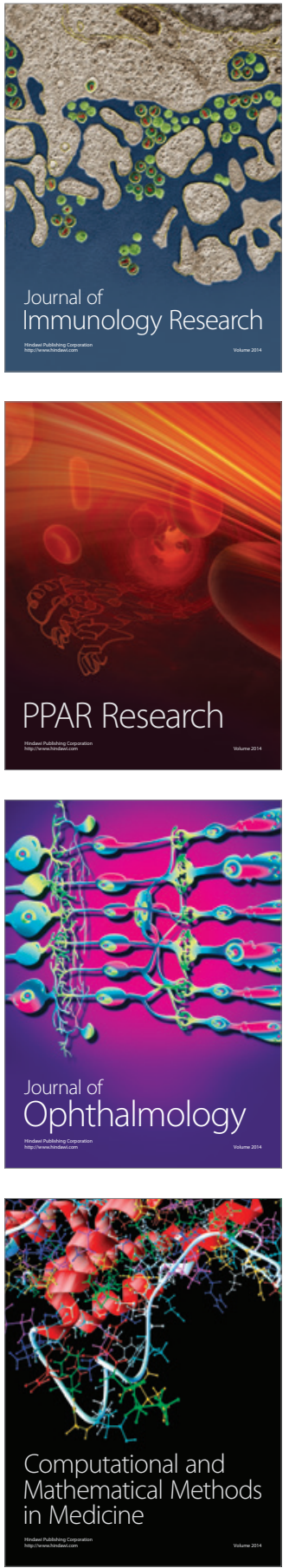

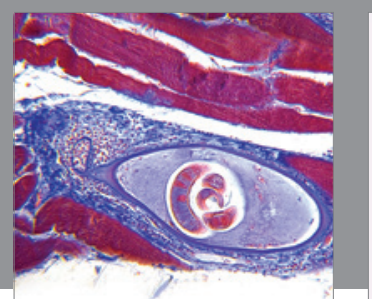

Gastroenterology Research and Practice

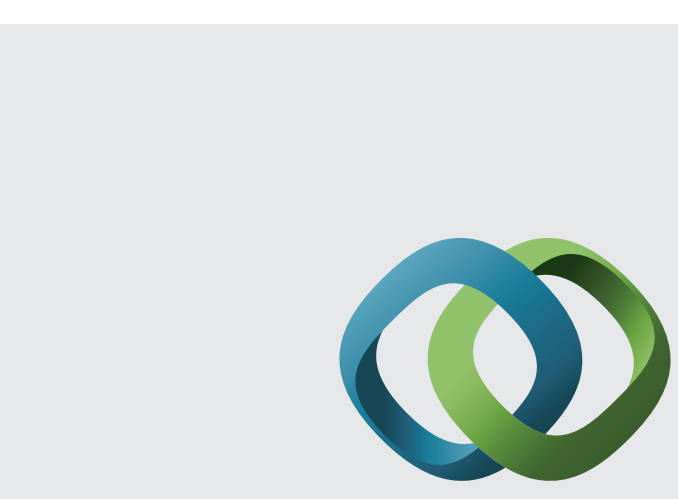

\section{Hindawi}

Submit your manuscripts at

http://www.hindawi.com
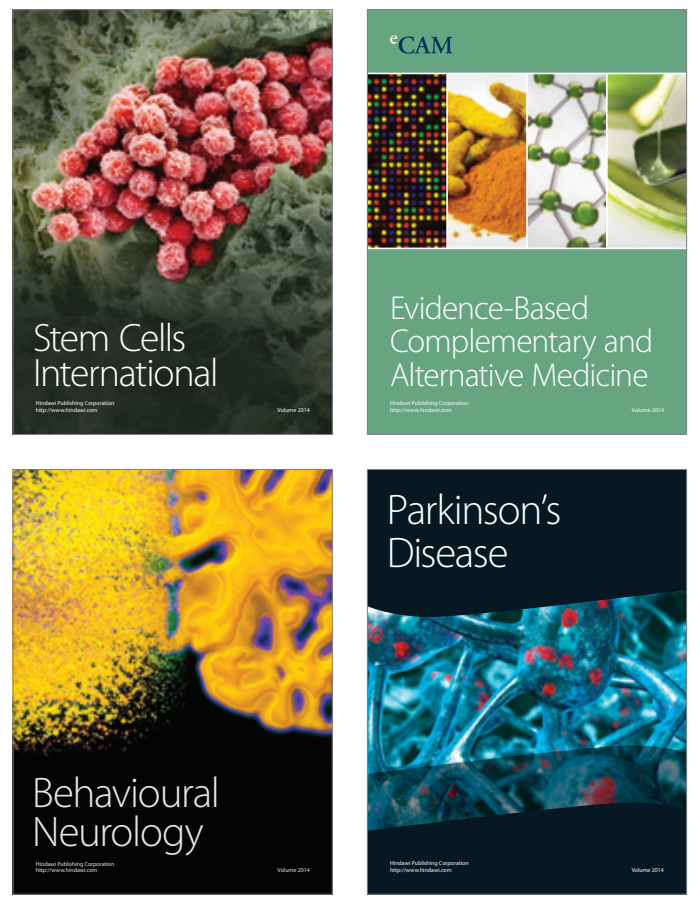
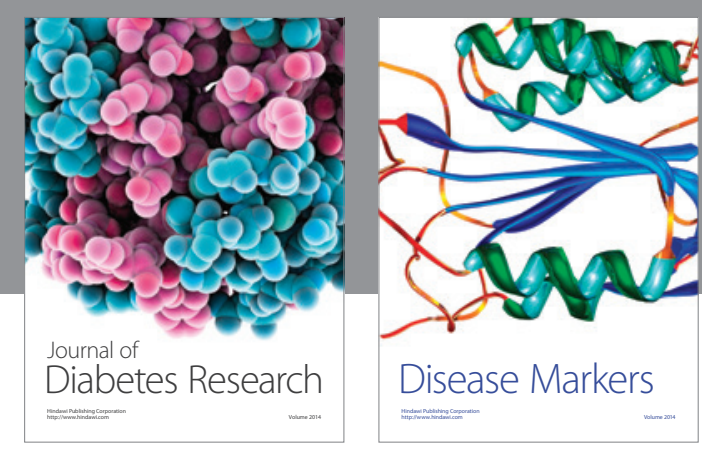

Disease Markers
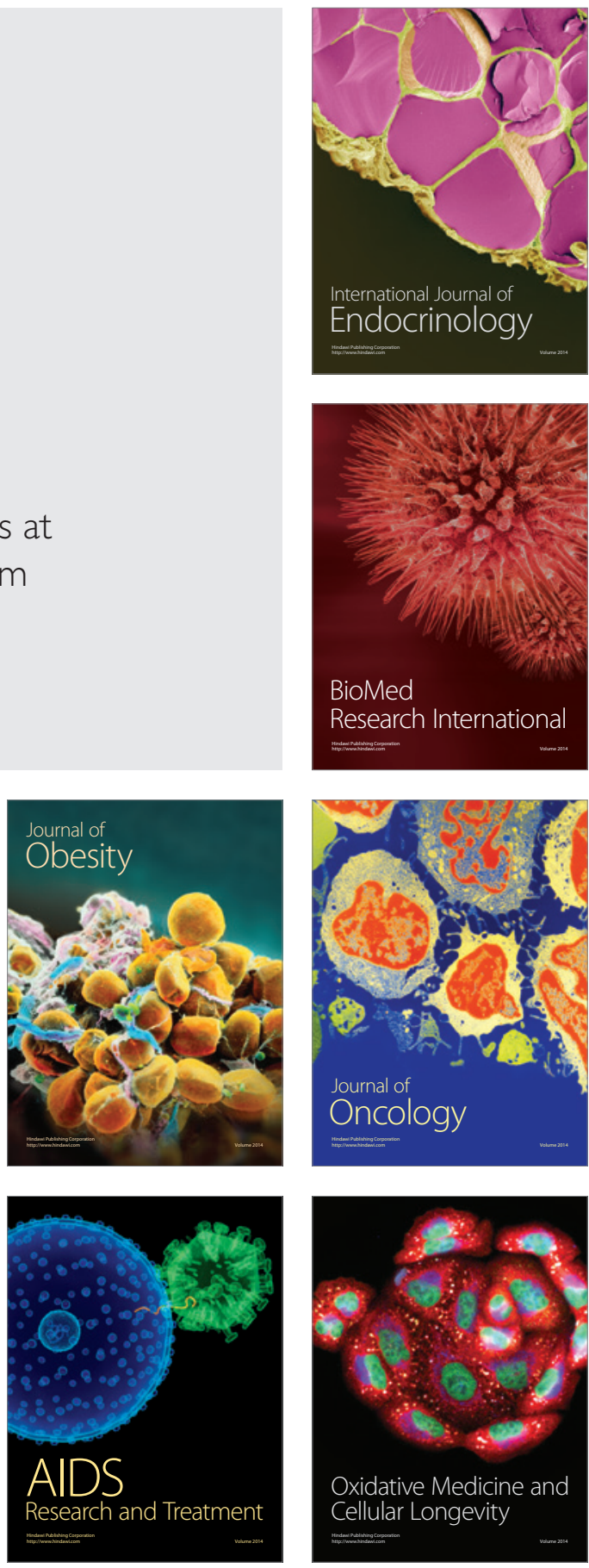